\title{
Health Impact Assessment: A Missed Opportunity for MCH Professionals in Their Quest to Address the Social Determinants of Health
}

\author{
James E. Dills ${ }^{1}$ (D) Taylor M. Lawson ${ }^{2} \cdot$ Jane Branscomb $^{1} \cdot$ Amy Mullenix $^{3} \cdot$ Kristen Hassmiller Lich $^{4}$
}

Accepted: 7 December 2021 / Published online: 24 January 2022

(c) The Author(s) 2022

\begin{abstract}
Introduction Public health professionals, especially ones concerned with maternal and child health (MCH), need to engage in cross-sector collaborations to address social determinants of health. Health Impact Assessment (HIA) systematically brings public health perspectives into non-health decision-making contexts that influence social determinants. Alignment of $\mathrm{MCH}$ and HIA practice has not previously been documented.

Methods An exploratory review of HIAs conducted in the United States considered several dimensions of MCH-HIA alignment and produced data to test the hypothesis that HIAs involving $\mathrm{MCH}$ stakeholders are more likely to address $\mathrm{MCH}$ populations and relevant measures. The review examined three key variables for each HIA: inclusion of MCH-focused stakeholders, level of focus on $\mathrm{MCH}$ populations, and presence of MCH-relevant content.

Results Of the 424 HIAs included in the database of US HIAs, 350 were included in this review. Twenty-four percent (84) included MCH-focused stakeholders, and 42\% (148) focused on $\mathrm{MCH}$ populations. Ninety percent (317) included metrics or content relevant to at least one Title V National Performance Measure (NPM). HIAs that clearly included MCH stakeholders had seven times the odds of including both a focus on $\mathrm{MCH}$ populations and at least one NPM-relevant topic compared to HIAs that did not clearly include MCH stakeholders (OR 6.98; 95\% CI 3.99, 12.20).

Discussion Despite low engagement of MCH stakeholders in HIAs, many still consider MCH populations and measures. Intentional engagement of $\mathrm{MCH}$ workforce in HIAs could ensure greater alignment with existing MCH priorities (such as addressing the social determinants of health and equity) in a given jurisdiction.
\end{abstract}

Keywords Social determinants of health $\cdot$ Equity $\cdot$ Policy $\cdot$ Maternal and child health workforce $\cdot$ Health impact assessment $\cdot$ Health in all policies $\cdot$ Systems integration

\section{Significance Statement}

James E. Dills

jdills@gsu.edu

1 Georgia Health Policy Center, Andrew Young School of Policy Studies, Georgia State University, 55 Park Place NE, 8th Floor, Atlanta, GA 30303, USA

2 Rollins School of Public Health, Emory University, Grace Crum Rollins Building, 1518 Clifton Road, Atlanta, GA 30322, USA

3 Gillings School of Global Public Health, University of North Carolina - Chapel Hill, 412 Rosenau Hall CB \#7445, Chapel Hill, NC 27599, USA

4 Gillings School of Global Public Health, University of North Carolina - Chapel Hill, 1105E McGavran-Greenberg Hall CB \#7411, Chapel Hill, NC 27599, USA
What is already known on this subject? Cross-sector collaboration has become increasingly important for public health practice. HIA is an effective tool for building collaborative relationships across sectors. The $\mathrm{MCH}$ workforce is in need of actionable frameworks for cross-sector collaboration to impact social determinants of health and equity.

What this study adds? HIA practice in the US has not seen extensive involvement of the $\mathrm{MCH}$ workforce, but it has regularly incorporated $\mathrm{MCH}-$ relevant content. By filling this gap and becoming more involved in HIA, $\mathrm{MCH}$ professionals have an opportunity to build cross-sector capacity and ensure relevance of $\mathrm{MCH}$ content. 


\section{Introduction}

Researchers, practitioners, and policy-makers need to address social determinants of health to meaningfully reduce population-level disparities and improve maternal and child health $(\mathrm{MCH})$. Social determinants of health are conditions in the environments where people are born, live, learn, work, play, worship, and age that affect a wide range of health, functioning, and quality-of-life outcomes and risks (U.S. Department of Health and Human Services Office of Disease Prevention and Health Promotion, 2018). Addressing disparities requires a commitment to health equity, which means striving for the highest possible standard of health for all people and giving special attention to needs of individuals at greatest risk based on social conditions (Braveman, 2014). The Maternal and Child Health Bureau of the Health Resources and Services Administration has emphasized a need for integrating perspectives of social determinants and equity into MCH practice (Fine et al., 2010). Meeting this need requires collaboration between public health and other sectors like education, housing, and transportation (DeSalvo et al., 2016; Koh et al., 2011; Mattessich \& Rausch, 2014).

Research on training needs of the public health workforce, and the MCH workforce specifically, emphasizes policy engagement and collaboration with sectors outside traditional public health silos as areas for improvement
(Bogaert et al., 2019; DeSalvo et al., 2017; Raskind et al., 2019; Sellers et al., 2015). As a result, the National MCH Workforce Development Center advances strategies to help Title V leaders and $\mathrm{MCH}$ practitioners build collaborative policy engagement capacity, using systems integration perspectives that emphasizes social determinants of health and equity (Clarke \& Cilenti, 2018; Margolis et al., 2017). One of these strategies is implementing a Health in All Policies (HiAP) approach.

HiAP considers how to systematically integrate public health perspectives on social determinants and equity into decision-making across non-health sectors (Ståhl et al., 2006; Wernham \& Teutsch, 2015). One of the more common HiAP approaches is health impact assessment (HIA) (Gase et al., 2013; Rudolph et al., 2013). The National Research Council defines HIA as:

A systematic process that uses an array of data sources and analytic methods and considers input from stakeholders to determine the potential effects of a proposed policy, plan, program, or project on the health of a population and the distribution of those effects within the population. HIA provides recommendations on monitoring and managing those effects (2011).

While variations exist in practice, conducting HIA typically involves the iterative six-step process illustrated in

Table 1 Six steps of health impact assessment and associated outputs (National Research Council, 2011)

\begin{tabular}{|c|c|}
\hline Step & Outputs \\
\hline Screening & $\begin{array}{l}\text { Describes proposed policy, program, plan, or project, including timeline for decision and political and policy context } \\
\text { Presents preliminary opinion on importance of proposal for health and the opportunities for HIA to inform the deci- } \\
\text { sion, and states why the proposal was selected for screening } \\
\text { Outlines expected resource requirements to conduct HIA } \\
\text { Provides recommendation on whether HIA is warranted }\end{array}$ \\
\hline Scoping & $\begin{array}{l}\text { Summarizes pathways and health effects to be addressed, and provides rationale for those included and excluded } \\
\text { Identifies affected populations and vulnerable groups } \\
\text { Describes research questions, data sources, the analytic plan, data gaps, and how gaps will be addressed } \\
\text { Identifies alternatives to the proposed action to be assessed } \\
\text { Summarizes stakeholder engagement, issues raised by stakeholders, and responses to those issues }\end{array}$ \\
\hline Assessment & $\begin{array}{l}\text { Describes the baseline health status of affected populations } \\
\text { Analyzes and characterizes beneficial and adverse health effects of the proposal and each alternative } \\
\text { Describes data sources and analytic methods used } \\
\text { Documents stakeholder engagement and integrates input into analyses } \\
\text { Identifies clearly the limitations and uncertainties of the analysis }\end{array}$ \\
\hline Recommendations & $\begin{array}{l}\text { Identifies alternatives to proposal or actions that could be taken to avoid, minimize, or mitigate adverse effects and to } \\
\text { optimize beneficial ones } \\
\text { Proposes a health-management plan to identify stakeholders who could implement recommendations, indicators for } \\
\text { monitoring, and systems for verification }\end{array}$ \\
\hline Reporting & $\begin{array}{l}\text { Provides clear documentation of the proposal analyzed, the population affected, stakeholder engagement, data } \\
\text { sources and analytic methods used, findings, and recommendations } \\
\text { Communicates findings and recommendations to decision makers, the public, and other stakeholders in a form that } \\
\text { can be integrated with other decision-making factors (technical, social, political, and economic) }\end{array}$ \\
\hline Monitoring \& Evaluation & $\begin{array}{l}\text { Tracks changes in health indicators or implementation of HIA recommendations } \\
\text { Evaluates (a) whether the HIA was conducted according to its plan and applicable standards (process evaluation), (b) } \\
\text { whether the HIA influenced the decision-making process (impact evaluation), and (c) when practicable, whether } \\
\text { implementation of the proposal changed health indicators (outcome evaluation) }\end{array}$ \\
\hline
\end{tabular}


Table 2 Eight minimum elements of health impact assessments (Bhatia et al., 2014)

1. HIA is conducted to assess the potential health consequences of a proposed program, policy, project, or plan under consideration by decisionmakers, and is conducted in advance of the decision in question

2. HIA involves and engages stakeholders affected by the proposal, particularly vulnerable populations

3. HIA systematically considers the full range of potential impacts of the proposal on health determinants, health status, and health equity

4. HIA provides a profile of existing conditions for the populations affected by the proposal, including their health outcomes, health determinants, and vulnerable sub-groups within the population, relevant to the health issues examined in the HIA

5. HIA characterizes the proposal's impacts on health, health determinants, and health equity, while documenting data sources and analytic methods, quality of evidence used, methodological assumptions, and limitations

6. HIA provides recommendations, as needed, on feasible and effective actions to promote the positive health impacts and mitigate the negative health impacts of the decision, identifying, where appropriate, alternatives or modifications to the proposal

7. HIA produces a publicly accessible report that includes, at minimum, documentation of the HIA's purpose, findings, and recommendations, and either documentation of the processes and methods involved, or reference to an external source of documentation for these processes and methods. The report should be shared with decision-makers and other stakeholders

8. HIA proposes indicators, actions, and responsible parties, where indicated, for a plan to monitor the implementation of recommendations, as well as health effects and outcomes of the proposal

Table 1 and components of the eight Minimum Elements listed in Table 2 (Bhatia et al., 2014; Dannenberg, 2016a; National Research Council, 2011).

HIA is a practical tool for synthesizing evidence and stakeholder input to foster collaboration and inform decisions made outside the health sector (Cole \& Fielding, 2007). Because individual HIAs are primarily oriented toward practice, they are under-documented in peer-reviewed research literature. HIA researchers launched a dedicated journal in 2016 to address this issue and to provide more opportunities for HIA practitioners to publish their results (Stone, 2016). Over the past decade, published research on HIA in the United States has mostly considered effectiveness of the process, while individual case studies remain elusive in traditional research databases (Cole et al., 2019; Dannenberg, 2016b; Sohn et al., 2018). For example, searching the key words "health impact assessment" in PubMed returns a large number of results, but most are not specific to the prospective process defined above.

A PubMed search for "health impact assessment" conducted by the authors in January 2020 returned 1,264 results. When sorted by relevance, the first 100 results included 19 published accounts of specific HIAs, of which five were conducted in the United States. In the $\mathrm{MCH}$ context, even fewer research publications regarding HIA are available: as of January 2020, the Maternal and Child Health Journal has published no articles describing "Health Impact Assessment" in their title or abstracts. To the authors' knowledge, the current study is the first of its kind to document potential for alignment between $\mathrm{MCH}$ and HIA practice in the United States and to highlight the breadth of opportunities for $\mathrm{MCH}$ practitioners to engage in such HiAP initiatives as a strategy to address the social determinants of health.

\section{Methods}

\section{Research Overview and Key Questions}

This study leveraged a repository of HIAs conducted in the United States to answer these questions: (1) to what extent have $\mathrm{MCH}$-focused stakeholders been involved in HIA practice? (2) How often and to what extent do HIAs examine MCH subpopulations? (3) What proportion of HIAs include Title V National Performance Measures (NPMs) or closely related metrics in their analyses? (4) Are HIAs that engage $\mathrm{MCH}$-focused stakeholders more likely to include information on $\mathrm{MCH}$ populations and NPM-relevant content? Fig. 1 illustrates the interrelatedness of the four research questions. Collected data also characterize the breadth of non-health policies relevant to $\mathrm{MCH}$ outcomes and a range of opportunities for MCH stakeholders to inform them. This study does not include any clinical or patient data.

\section{Data Source and Inclusion Criteria}

The Health Impact Project, a collaboration of the Robert Wood Johnson Foundation and The Pew Charitable Trusts, hosts a web-based repository of information about HIAs conducted in the United States (Health Impact Project, 2017). HIA researchers commonly use this repository as a data source (Cole et al., 2019; Cowling et al., 2017; Dannenberg et al., 2019; Gase et al., 2017). Although uploading HIA information to the site is voluntary, this repository has been viewed as a largely complete picture of US practice since its inception in 2010.

As of September 2017, the repository listed 424 HIAs. The entry for each HIA includes hyperlinks and contextual data like project title, lead organization(s), decisionmaking level (local, regional, state, or federal), and target sector (e.g. housing, education, transportation, etc.). HIAs 
Fig. 1 Interrelatedness of four research questions guiding the review of HIAs

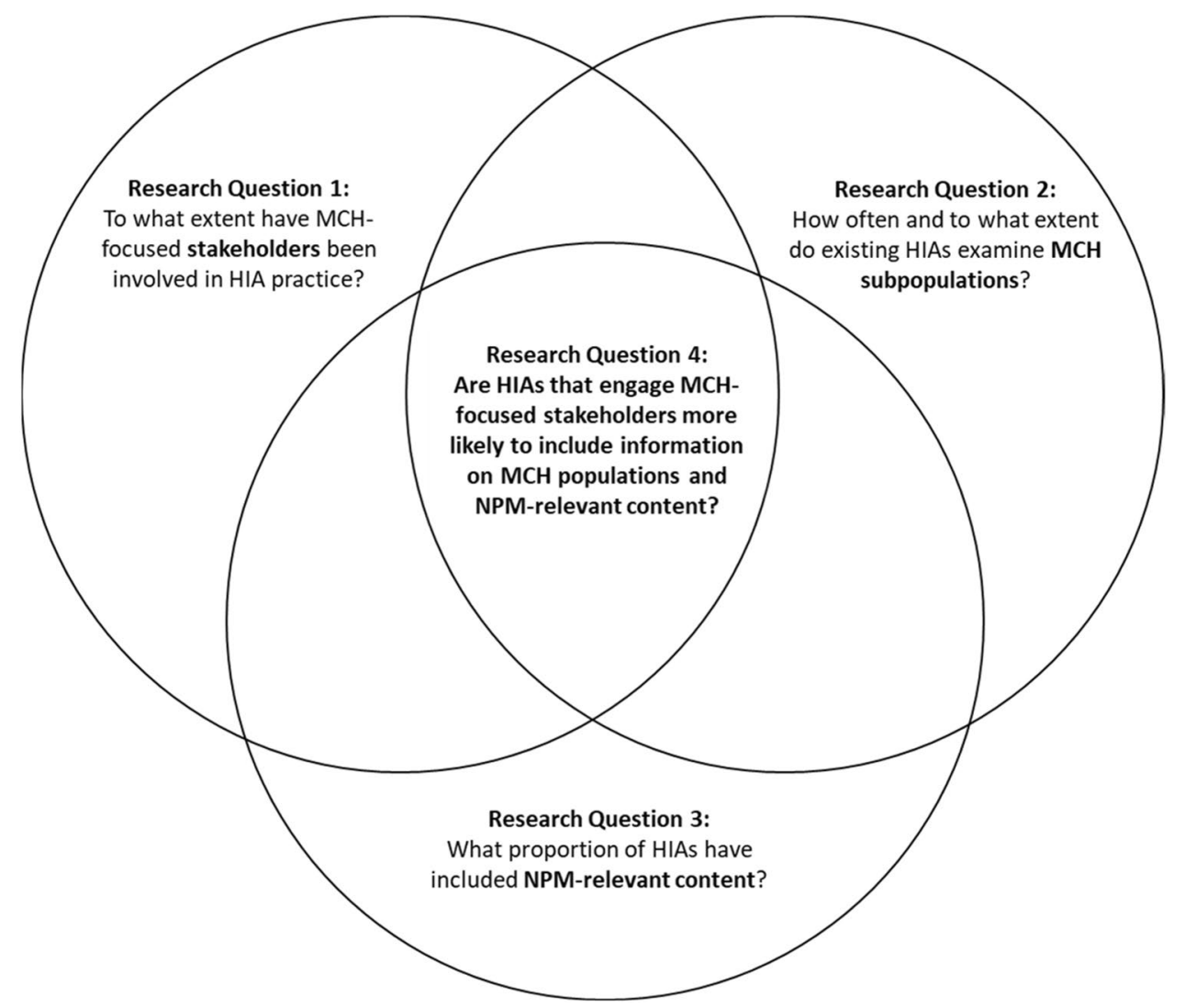

were excluded from the current analysis when project documentation was not available, either because the HIA was in progress or because available hyperlinks were no longer active and reviewers were unable to find publicly available documentation via web search based on HIA title and/or lead organization.

\section{Key Variables}

Researchers coded three primary variables for each HIA reviewed. First, they determined the involvement of $\mathrm{MCH}$ focused stakeholders. MCH-focused stakeholders included organizations or individuals that focus on infants, children, youth, adolescents, mothers, pregnant individuals, and/or families. State or Local Health Departments were only included as $\mathrm{MCH}$-focused stakeholders if available documentation clearly noted representation from an $\mathrm{MCH}-$ serving division, branch, or team (e.g. the Title V Office, Division of Child Health, etc.). Reviewers did not assume inclusion of these perspectives unless stated. This variable was coded 'yes' if documentation revealed an explicit role for an $\mathrm{MCH}$-focused partner in the conduct of the HIA, ranging from roles on the HIA project team or advisory committee to participation in document review or data collection as part of the process. If available documentation mentioned $\mathrm{MCH}$-focused stakeholders but was unclear about the extent of involvement, reviewers coded this variable as 'partial.' The 'partial' designation was also used when the reviewer was unsure about the extent to which a given stakeholder explicitly focused on $\mathrm{MCH}$, for example local educational institutions were regularly placed in this category.

The second variable considers attention given to $\mathrm{MCH}$ populations within the HIA. MCH populations include infants, children, youth, adolescents, mothers, pregnant individuals, and/or families. Reviewers coded this variable as 'yes' if documentation noted explicit focus on one or more of these MCH populations as part of the HIA scope. This meant that the HIA not only identified an $\mathrm{MCH}$ population as a subpopulation of concern, but that the assessment and/or recommendations reflect elevated attention on that group. Reviewers assigned a 'partial' designation if the HIA mentioned $\mathrm{MCH}$ populations but did not clearly incorporate them as part of the assessment. This included instances where a report includes statistics on an $\mathrm{MCH}$ population but not as a critical element of the analysis (e.g. the childhood 
obesity rate was mentioned as part of existing conditions but not in the assessment of potential impacts).

To define the third key variable, inclusion of $\mathrm{MCH}$ content, reviewers determined whether each HIA included topics related to one or more of the Title V NPMs. These 15 measures were selected as the basis for defining "MCH content" in this review because national leaders have identified them as foundational to the work of public health $\mathrm{MCH}$ professionals, as measurable, as directly modifiable by states' programmatic activities, and as meaningful when changed (Kogan et al., 2015). Specific guidance and search terms were developed for each NPM and are listed in Table 3, along with examples of reviewer notes from specific HIAs. Reviewers only used the 'yes' designation when the exact NPM was noted in the HIA. They used the 'partial' designation when an NPM topic was touched upon in the HIA, but without including the exact NPM. A goal of this review is to inspire $\mathrm{MCH}$ professionals toward more upstream cross-sector engagement and collaboration by documenting the breadth of opportunities where their perspectives could have been valuable in existing HIA practice. Because this retrospective accounting of opportunities was generated from content positioned primarily within non-MCH perspectives, the authors were intentionally inclusive in identifying aspects of a given HIA that could be considered $\mathrm{MCH}-$ relevant content, and thus, some instances may stretch the bounds of what is considered closely related to specific NPMs.

\section{Review and Extraction Process}

Starting with information available in Health Impact Project's repository, researchers followed a protocol created and pilot-tested specifically for this review. First, they used project hyperlinks to obtain publicly available HIA documentation. This documentation was then reviewed to determine designations for the three key variables described above. In addition to a scan of available documentation for each HIA, variable-specific search terms were employed to more efficiently identify relevant content. Reviewers extracted this relevant content and summarized how it supported designations of 'yes', 'partial', or 'no' for each variable. A pilottest of the protocol on 20 randomly selected HIAs included independent review of each by three researchers, who agreed $85 \%$ of the time across all variable designations. No HIA in the pilot explicitly included any of the 15 NPMs, which led researchers to adjust the final review protocol for this variable to be more inclusive of related content within the 'partial' designation. Two co-authors then collaboratively reviewed the remaining HIAs and adjudicated disagreements through discussion as needed. When reviewers could not make a clear determination, the research team made a final coding determination based on collective interpretation of the available content in the context of the study objectives. Reviewers applied the protocol to available materials and coded responses into an Excel spreadsheet.

\section{Analysis}

Coded data were transferred to SPSS (IBM Corp., 2017), and frequency tables were produced for each research question. Upon initial review of the data, yes/partial/no responses were recoded to facilitate statistical analysis and hypothesis testing. For the MCH stakeholder and MCH population variables, 'no' and 'partial' responses were combined to allow dichotomous comparison to the 'yes' responses. Because so few HIAs were coded as 'yes' for including NPMs, responses for this variable were dichotomized by combining 'yes' and 'partial' designations for comparison with those HIAs designated as 'no.' Researchers also created a variable that indicated the total number of NPMs each HIA addressed, ranging from 0 to 15 .

To test the hypothesis that HIAs with MCH stakeholder involvement are more likely to include a focus on $\mathrm{MCH}$ populations and NPM-related topics, a single dichotomous dependent variable was created that combined inclusion of $\mathrm{MCH}$ populations and NPM-relevant topics. These binary data were used to conduct Chi-Square and Simple Odds Ratios to test the hypothesis. Statistical significance was determined at alpha $=0.05$.

\section{Results}

Figure 2 illustrates how the 424 HIAs contained in the Health Impact Project database were narrowed to an analysis sample of 350 HIAs.

Research Question 1: To what extent have $\mathrm{MCH}$ focused stakeholders been involved in HIA practice?

Slightly less than one quarter (24\%) of the 350 HIAs reviewed demonstrated clear inclusion of $\mathrm{MCH}$ stakeholders (Fig. 3). The only example of an HIA that clearly indicated inclusion of a Title $\mathrm{V}$ agency considered impacts of potential changes to paid sick leave policy in Vermont (Vermont Department of Health, 2015). In that HIA, led by the Vermont Department of Health, representatives from the Division of Maternal and Child Health were listed as stakeholders, along with the Vermont Commission on Women, several school nurses, and a local child care facility. Under the definition of stakeholders described above, the most common stakeholder groups were school or other education system representatives and child or family-focused advocacy 
Table 3 Specific guidance for HIA reviewers used to characterize NPM inclusion

Title V National Performance Measure (NPM)

NPM 1: Well-Woman Visit

(Percent of women with a past year preventive medical visit)

NPM 2: Low-Risk Cesarean Delivery

(Percent of cesarean deliveries among low-risk first births)

NPM 3: Risk-Appropriate Perinatal Care

(Percent of very low birth weight (VLBW) infants born in a hospital with a Level III + Neonatal Intensive Care Unit (NICU))

NPM 4: Breastfeeding

(A) Percent of infants who are ever breastfed and (B) Percent of infants breastfed exclusively through 6 months)
HIA Review search terms and coding guidance

Search Terms: women, woman, preventive

Guidance to Reviewers: This NPM is concerned with preventive care for women. HIAs may include other measures of preventive care use by women, and instances should be included and explained as part of the review

Example from Review Data: "Among women, close to half (47.7\%) indicated that they had visited an obstetrician or gynecologist in the past year" (p. 62).-A Health Impact Assessment of the Healthy Families Act of 2009 (Federal)

Search Terms: birth, Cesarean

Guidance to Reviewers: This NPM considers Low-risk Cesarean delivery and did not come into play during the pilot reviews. Any instance of an HIA mentioning Cesarean births should be included in order to prompt further discussion

Example from Review Data: Maternity leave (paid) for women who have a cesarean birth (Table 2 on page 17). Also see "Health care providers, however, strongly believe that at a very minimum 6 weeks is required for a mother to recover from a normal childbirth and up to 3 months is required after a complicated or caesarian delivery" (p. 30).-Pathways to a Healthy Decatur:

A Rapid Health Impact Assessment of the City of Decatur Community Transportation Plan (Georgia) - 2007

Search Terms: perinatal, birth, weight, birthweight

Guidance to Reviewers: A number of HIAs are likely to note low birth weight as an outcome associated with (most commonly) air pollution. While this type of information is not exactly the same as that describing the care received by very low birth weight infants, as reflected in the NPM (Risk-Appropriate Perinatal Care), noting any consideration of birthweight in this column is still important for the purpose of this review

Example from Review Data: Low birth weight and preterm births are discussed multiple times throughout the HIA, particularly in connection to food insecurity and unhealthy eating for pregnant individuals. Tables and analysis provide information on low birth weight and preterm birth, specifically.—A Health Impact Assessment of a Food Tax in New Mexico: An analysis of the taxation of grocery purchases and its impacts on the health of the state's children, families, and communities-2015)

Search Terms: breast

Guidance to Reviewers: Breastfeeding did not come up in any of the pilot HIAs and is likely to be rare in the larger sample, so be inclusive of any mention of breastfeeding for this review

Example from Review Data: "Barriers to breastfeeding among WIC participants have included sore nipples and pain, perceptions of inadequate milk supply, and social support networks' attitudes about breastfeeding. It is possible that these barriers would be heightened for homeless women because of inadequate access to lactation resources, concerns about inadequate milk production, or because of returning to the workforce" (p. 105)._planokc Comprehensive Plan

Health Impact Assessment (Oklahoma City)—2014 
Table 3 (continued)

Title V National Performance Measure (NPM)

NPM 5: Safe Sleep

(Percent of infants placed to sleep on their backs)

NPM 6: Developmental Screening

(Percent of children, ages 10 through 71 months, receiving a developmental screening using a parent-completed screening tool)

NPM 7: Injury Hospitalization

(Rate of hospitalization for non-fatal injury per 100,000 children ages 0 through 9 and adolescents 10 through 19)
HIA Review search terms and coding guidance

Search Terms: sleep, infant

Guidance to Reviewers: Some HIAs in the pilot noted a connection between health, sleep, and noise exposure. The larger review is therefore expected to encounter this issue again. In cases where sleep and/ or sleep disturbance are considered, only include under this column if documentation notes a specific tie to infants. The NPM is concerned with a specific safe sleep practice (percent of infants placed to sleep on their backs), and while we anticipate few (if any) HIAs will directly consider this indicator, it will be useful to consider ones that touch on infant sleep at all as getting 'close' to this measure

Example from Review Data: "Aircraft noise in the late evening has also been shown to disturb sleep among adults and infants" (p. 26).-_Health Impact Assessment (HIA) of Cargo Atlanta: a Citywide Freight Study-2016

Search Terms: Developmental, Screening. Note: 'Screening' is likely to generate false positives because it describes a step in the HIA process Guidance to Reviewers: This NPM focuses on developmental screening of youth up through age 5 (71 months) and appears unlikely to be directly addressed in existing HIAs; however, there may be instances where the physical and/or mental development of young children get discussed in an HIA. In these instances, be inclusive so we can return to them for further discussion

Example from Review Data: "PCBs and mercury. Human consumption of these fish can lead to chronic health problems, and children are at the greatest risk for developmental effects from such exposure." (p. 52). Development is also discussed in connection with parks/green spaces, particularly for children with ADHD.-SR 520 Health Impact Assessment: A bridge to a healthier community (Seattle)—2008

Search Terms: injury, injuries, safe

Guidance to Reviewers: Injuries will be one of the more common topics included in HIAs, especially ones focused on transportation-related decisions. Include any mention of statistics related to injury (mortality and morbidity; intentional and unintentional) here and note where youth injuries are called out specifically. To be inclusive, also consider when perceptions of injury risk are being discussed. Likely to get very 'close' on this NPM, but only count as 'yes' over 'partial' if all the exact components of the NPM are noted: Rate of hospitalization for non-fatal injury per 100,000 children ages 0 through 9 and adolescents 10 through 19

Example from Review Data: "In addition, among accidental injuries that result in death for Baltimore children ages 1-17, 39\% are motor vehicle-related. Nearly two-thirds of these deaths involved a child who was walking or biking" (p. 16).-The Red Line Transit Project Health Impact Assessment (Baltimore)—2008 
Table 3 (continued)

Title V National Performance Measure (NPM)

NPM 8: Physical Activity

(Percent of children ages 6 through 11 and adolescents 12 through 17 who are physically active at least 60 min per day)

NPM 9: Bullying

(Percent of adolescents, ages 12 through 17, who are bullied or who bully others)

NPM 10: Adolescent Well-Visit

(Percent of adolescents, ages 12 through 17, with a preventive medical visit in the past year)
HIA Review search terms and coding guidance

Search Terms: physical activity, children

Guidance to Reviewers: Physical activity (PA) will also be among the most common topics addressed in the HIAs, allowing for us to be a little more conservative on inclusion. When PA statistics are given that would cover children or youth (anyone under age 19), include it as at least a 'partial'. There may be instances where all the data presented are for adult PA, but the discussion includes youth promotion. Capture these instances as a partial with explanation here and/or in the columns considering inclusion of MCH populations. If the HIA is only focused on adult PA and has no mention of the non-adult population, mark it as a 'no'. As with the injury NPM, HIAs are expected to get very 'close' on this NPM, but only denote it as a 'yes' over a 'partial' if all the exact components of the NPM are noted: percent of children ages 6 through 11 and adolescents 12 through 17 who are physically active at least $60 \mathrm{~min}$ per day

Example from Review Data: "Children who began and maintained physical activity levels into young adulthood had better mental health outcomes than children who were inactive or those who did not maintain physical activity levels" (p. 15).-Winona County Active Living Plan HIA (Minnesota)—2015

Search Terms: bully

Guidance to Reviewers: In the pilot, at least one HIA came up for discussion under this NPM. While it did not directly note bullying or measures thereof, the assessment did spend some time discussing possible impacts on student behavior/disruption in school, which could include bullying. To be inclusive, use your judgement as to whether or not any mentions of youth behavior in school or other social settings might include bullying

Example from Review Data: "Studies that have examined how social capital is reflected in children's health and educational outcomes suggest the effect is positive on behavior problems" (p. 43). Also"Another study notes that among victims of child maltreatment, psychological problems are prevalent and often manifest in aggressive behaviors towards both adults and peers," (p. 44).-CTransitional Jobs Programs: A Health Impact Assessment (Wisconsin)-2013

Search Terms: well-visit, adolescent

Guidance to Reviewers: Similar to NPM 1, this NPM is focused on preventive care-in this case for youth. While no instances occurred in the pilot, there may be times when data on aspects of youth prevention are included. Use your judgement, but err on the side of inclusivity since presence of this topic is likely to be a rare instance within the HIAs

Example from Review Data: Access to healthcare for children and adolescents-"More broadly, in a comparison study of schools with and without [school-based health centers], [Denver Health's SchoolBased Health Centers] located within school were more effective at reducing barriers to care and increasing access to and use of health care services for children and adolescents" (p. 21).-Addressing Mental Health and Physical Activity in K-12 Children in Colorado Springs: A Health Impact Assessment-2016 
Table 3 (continued)

Title V National Performance Measure (NPM)

NPM 11: Medical Home

(Percent of children with and without special health care needs having a medical home)

\section{NPM 12: Transition}

(Percent of adolescents with and without special health care needs who received services necessary to make transitions to adult health care)

NPM 13: Preventive Dental Visit

(A) Percent of women who had a dental visit during pregnancy and (B) Percent of children, ages 1 through 17 who had a preventive dental visit in the past year)
HIA Review search terms and coding guidance

Search Terms: medical home, special needs

Guidance to Reviewers: This NPM is unlikely to be directly addressed in many HIAs, but topics like youth insurance coverage and health care utilization might arise. Use your judgement and err on the side of inclusiveness, but only when children/youth are explicitly considered. Also relevant here are youth with special needs. Include the mention of children and youth with special needs under the MCH Populations columns unless the HIA explicitly discusses access to health care for that group, in which case it would fit under this NPM discussion as well

Example from Review Data: "In North Carolina, children with disabilities are classified as children with special health care needs (CSHCN), defined as "children who need prescription medications or have an elevated need for medical, mental health, or education services due to a medical, behavioral, or other health condition that has lasted or is expected to last for at least 12 months.' According to results of the 2011 NC Child Health Assessment and Monitoring Program (CHAMP), $18 \%$ of children ages $0-17$ are considered CSHCN. Using this percentage and 2010 U.S. Census data $(2,500$ children in Davidson), approximately 450 children within Davidson would be considered CSHCN" (p. 8).-Universal Design in Single-Family Housing: A Health Impact Assessment (HIA) in Davidson, NC-2013

Search Terms: transition, adolescent, special needs Guidance to Reviewers: (Similar to NPM 11) This NPM is unlikely to be directly addressed in many HIAs, but topics like youth insurance coverage and health care utilization might arise. Use your judgement and err on the side of inclusiveness, but only when older youth are explicitly considered. Also relevant here are youth with special needs. Include the mention of children and youth with special needs under the MCH Populations columns unless the HIA explicitly discusses access to health care for that group, in which case it would fit under this NPM discussion if age-specific aspects are considered

Example from Review Data: "Assure the availability of a medical home for all to increase age-specific health screening and preventative care" (p. 23).-Buncombe County Greenways \& Trails Master Plan Health Impact Assessment (North Carolina)—2013

Search Terms: dental, dentist, oral, oral health Guidance to Reviewers: Few HIAs are likely to include oral health, much less for women and children specifically. To be inclusive, note any references to oral health found during your search, as 'partial' with explanation to inform future discussion

Example from Review Data: "According to a survey performed by the National Energy Assistance Directors Association (NEADA) in 2005, a significant proportion of LIHEAP participants in the Northeast reported making precisely these kinds of budget trade-offs due to high energy costs:... 28\% went without medical or dental care;" (pp. 2-3). Also see "Housing instability and homelessness pose welldocumented threats to child physical health-have 10 times more dental caries than housed children" (p. 8).-Unhealthy Consequences: Energy Costs and Child Health|A Child Health Impact Assessment of Energy Costs and the Low Income Home Energy Assistance Program (Massachusetts)—2007 
Table 3 (continued)

Title V National Performance Measure (NPM)

NPM 14: Smoking

(A) Percent of women who smoke during pregnancy and (B) Percent of children who live in households where someone smokes)

NPM 15: Adequate Insurance

(Percent of children ages 0 through 17 who are adequately insured)
HIA Review search terms and coding guidance

Search Terms: smoke, smoking, tobacco

Guidance to Reviewers: This topic did not come up in the pilot reviews.

Include instances that consider smoking and second-hand smoke as 'partial' and explain

Example from Review Data: "Parks and recreational facilities should

be a smoke-free environment to reduce exposure to secondhand smoke - especially for youth who respire more frequently than adults while being physically active" (p. 10)._- One in five children is exposed to secondhand smoke in cars. Switching from car to bus, where smoking is not allowed, could help decrease children's exposure to secondhand smoke" (p. 23).-Potential Health Effects of Proposed Public Transit Concepts in Wichita, Kansas-2013

Search Terms: insurance, insured

Guidance to Reviewers: If the HIA talks about how a decision could influence the rate of individuals or families that have insurance, be inclusive. Highlight when/if the discussion is specific to youth

Example from Review Data: "Most students receive medical insurance via Medicaid (93\%), while $2 \%$ have private insurance and $5 \%$ of the students have no form of insurance at all." (p. 8).-Health Impact Assessment of the Demolition of a Lead Painted Bridge Adjacent to a Residential Area (Cincinnati)—2013

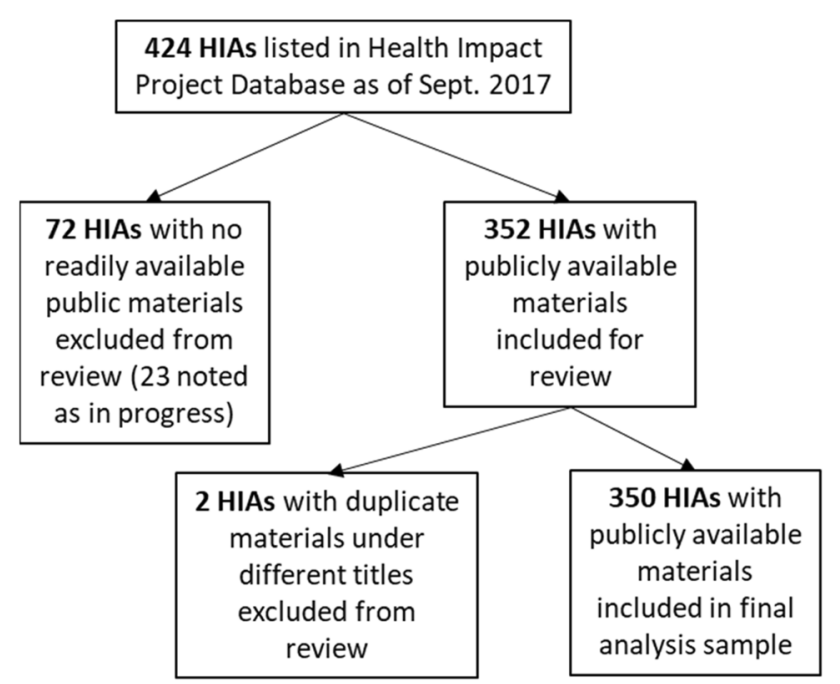

Fig. 2 Inclusion diagram organizations, noted in $42 \%$ and $39 \%$ of HIAs coded as including $\mathrm{MCH}$ stakeholders, respectively.

Research Question 2: How often do and to what extent do HIAs examine MCH subpopulations?

Eighty-four percent of the $350 \mathrm{HIAs}$ reviewed at least partially considered $\mathrm{MCH}$ populations according to publicly available materials. As illustrated in Fig. 4, this 84\% was split almost equally between HIAs designated as having a clear focus on MCH subpopulations (148 HIAs) and HIAs that only partially included them (147 HIAs).

Research Question 3: What proportion of HIAs include

Title V National Performance Measures (NPMs) or closely related metrics in their analyses?

Eighty-nine percent of the 350 HIAs included information designated as closely related to or relevant for at least one NPM, and less than $2 \%$ included specific NPMs. The
Fig. $3 \mathrm{MCH}$ stakeholder inclusion in HIAs

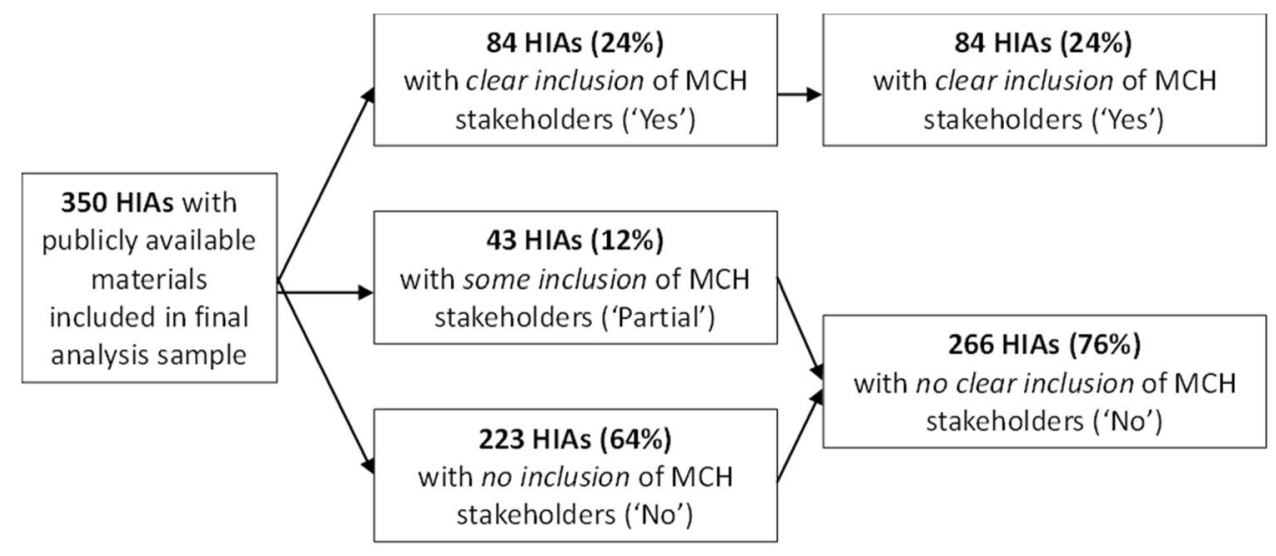


Fig. $4 \mathrm{MCH}$ population inclusion in HIAs

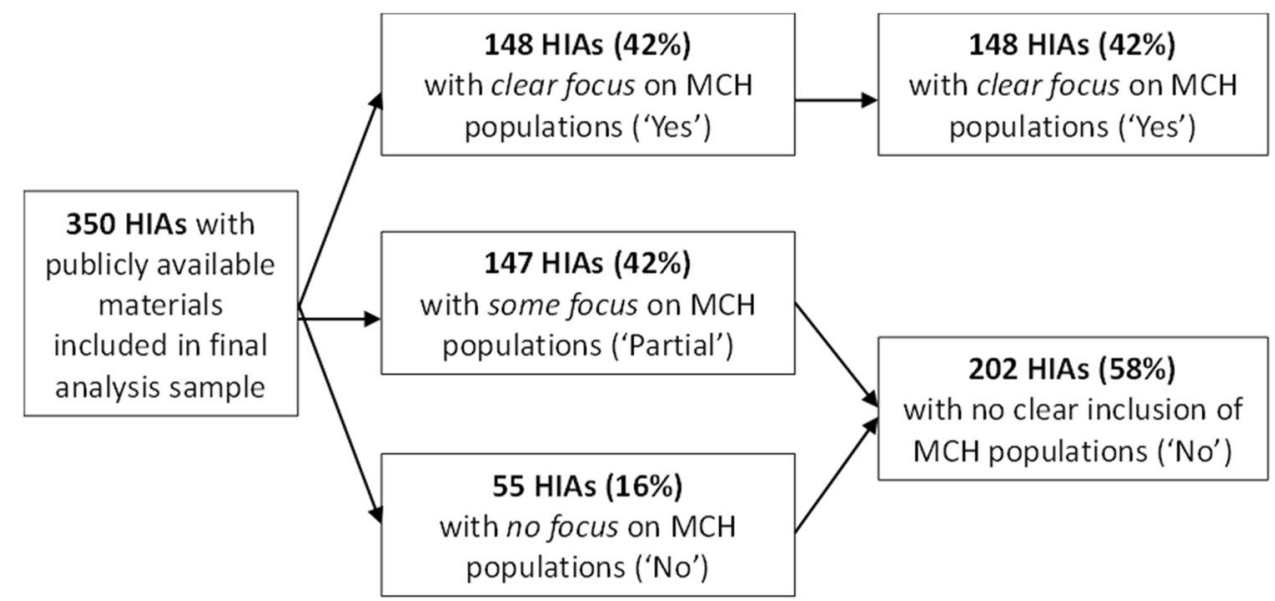

120

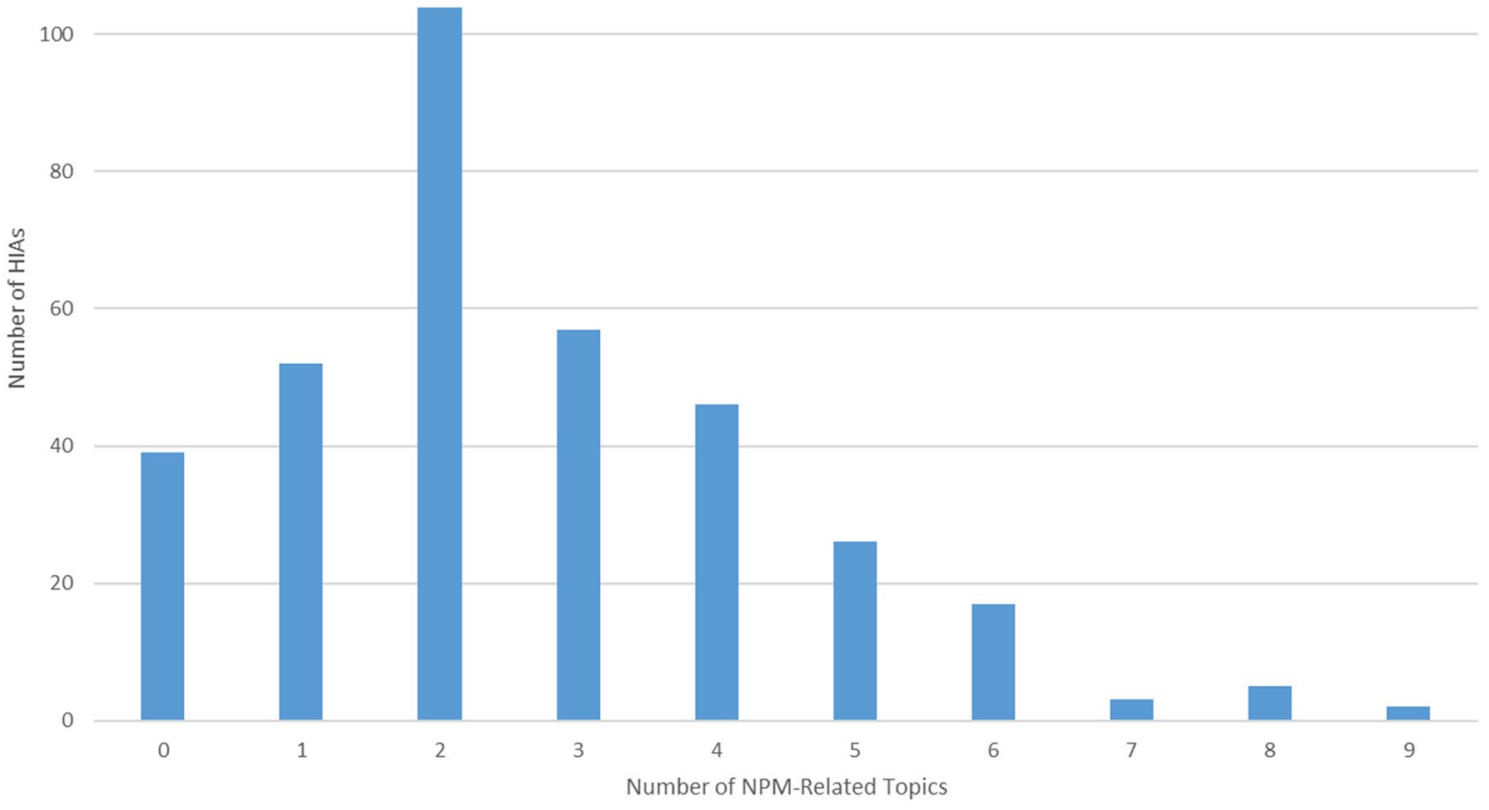

Fig. 5 Frequency of HIAs by number of NPM-related topics included

mean number of NPM-related topics included in an HIA was 2.62 (SD 1.80). The largest proportion of HIAs (30\%) included two NPMs, and most (61\%) included one to three topics (Fig. 5). All 15 NPMs were represented at least once across all HIAs reviewed (Fig. 6).

Injury and physical activity were the most common NPM-related topics, included in $61 \%$ and $59 \%$ of the 350 HIAs reviewed, respectively. None of the 214 HIAs including information about injuries used the specific NPM. However, all of them referenced injuries and hospitalizations in a way determined by reviewers to be relevant for $\mathrm{MCH}$ populations or practice. For physical activity, only one of the
205 HIAs coded as relevant for NPM 8 specifically included NPM itself.

Research Question 4: Are HIAs that engage MCHfocused stakeholders more likely to include information on MCH populations and NPM-relevant content?

The MCH stakeholder, MCH population, and NPM inclusion variables described above were used to test the hypothesis that HIAs involving MCH stakeholders are more likely to address both $\mathrm{MCH}$ populations and relevant measures. $\mathrm{MCH}$ stakeholder inclusion was the independent variable and dichotomized into HIAs with clear inclusion of $\mathrm{MCH}$ 


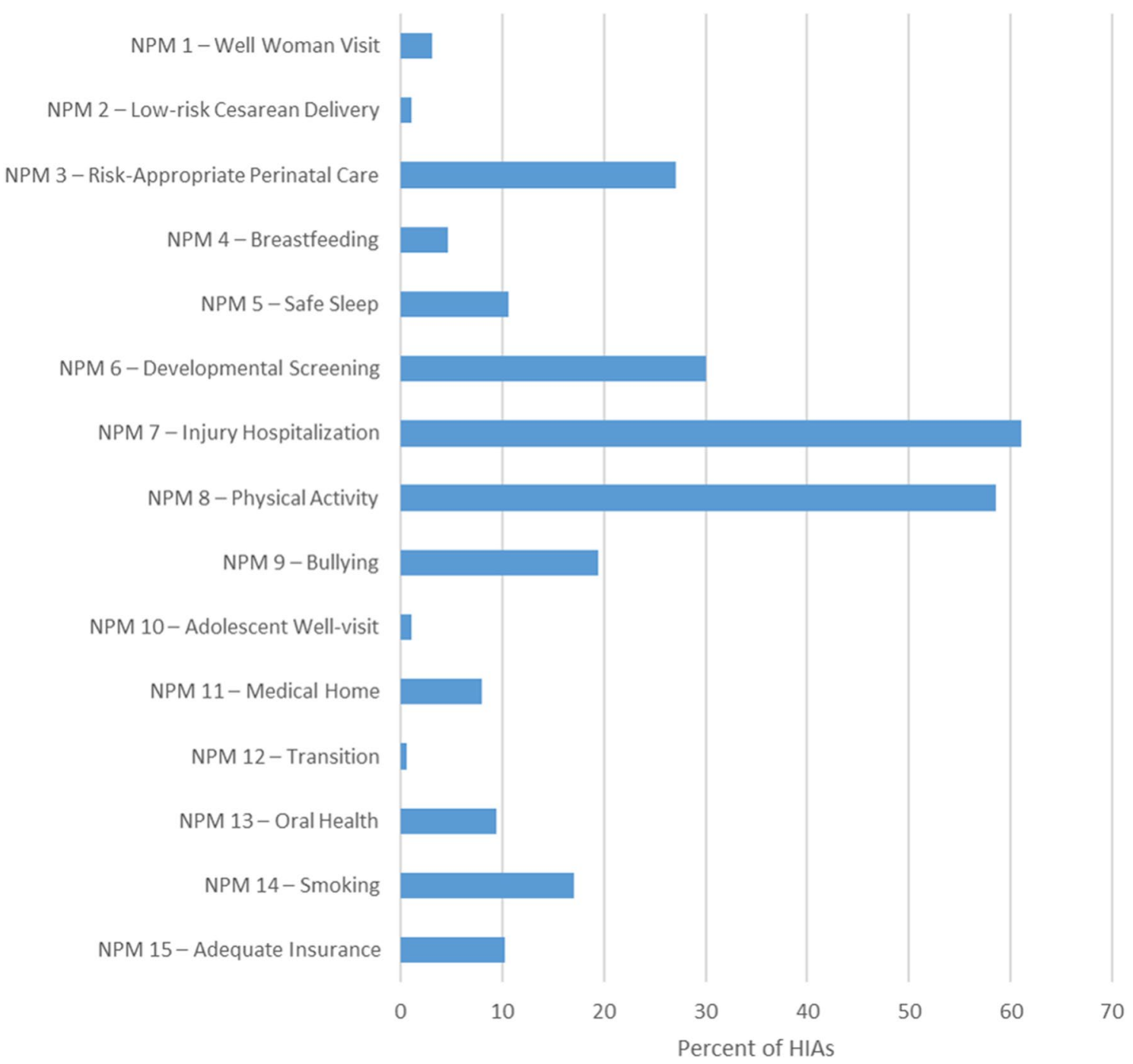

Fig. 6 Percent of HIAs including each NPM-related topic

stakeholders (designated by reviewers as 'yes'; $24 \%$ of the sample, $84 \mathrm{HIAs}$ ) and ones with no clear inclusion of $\mathrm{MCH}$ stakeholders (designated as either 'partial' or 'no'; 76\% of the sample, 266 HIAs). The dependent variable was a combination of MCH population focus and inclusion of NPMrelated topics, where an HIA had to satisfy both conditions to be coded as 'yes' ( $41 \%$ of the sample, 143 HIAs).

HIAs that clearly included MCH stakeholders had seven times the odds of including both a focus on $\mathrm{MCH}$ populations and at least one NPM-relevant topic compared to HIAs that did not clearly include MCH stakeholders (OR 6.98; 95\% CI 3.99, 12.20). This association is statistically significant (Chi-square, $\mathrm{p}<0.001)$. Table 4 displays the distribution across these two variables.

To demonstrate the breadth of non-health policies informed by HIA, Table 5 includes the distribution of HIAs across different target sectors. Table 6 summarizes ten HIAs that illustrate the range of potential opportunities for $\mathrm{MCH}$ engagement in this type of cross-sector collaboration. These examples were selected to reflect variation in the three key review variables and in two key contextual factors: target sector and decision-making level (local, regional, state, or federal). They were also chosen to reflect the geographic diversity in HIA practice in the US.

\section{Discussion}

Nearly all HIAs reviewed (95\%) considered an $\mathrm{MCH}$ population in some way or included information relevant to at least one NPM. In contrast, just over a third (36\%) contained evidence of $\mathrm{MCH}$ stakeholder involvement. The current analysis demonstrates that $\mathrm{MCH}$ stakeholder involvement in an HIA is associated with greater odds of that HIA 
Table 4 Inclusion of $\mathrm{MCH}$ stakeholders by $\mathrm{MCH}$ population focus and NPM-related topics

\begin{tabular}{cll}
\hline & $\begin{array}{l}\text { HIAs with clear focus } \\
\text { on MCH populations } \\
\text { AND with NPM-related } \\
\text { topics } \\
(\% \text { of total sample) }\end{array}$ & $\begin{array}{l}\text { HIAs with no clear } \\
\text { inclusion of MCH } \\
\text { populations OR without } \\
\text { NPM-related topics } \\
(\% \text { of total sample })\end{array}$ \\
\hline $\begin{array}{c}\text { HIAs with clear } \\
\text { inclusion of } \\
\text { MCH stake- } \\
\text { holders }\end{array}$ & 63 & 21 \\
$\begin{array}{c}\text { HIAs with no } \\
\text { clear inclu- } \\
\text { sion of MCH } \\
\text { stakeholders }\end{array}$ & 80 & $(6 \%)$ \\
\hline
\end{tabular}

addressing $\mathrm{MCH}$ populations and relevant topics, suggesting an opportunity for $\mathrm{MCH}$ professionals and HIA practitioners to engage with one another in strategic efforts to inform decisions made outside the traditional public health sector. Aligning these efforts allows both $\mathrm{MCH}$ professionals and HIA practitioners to better advance a "Public Health 3.0" approach, wherein public health leaders partner across multiple sectors to address social, environmental, and economic conditions that affect health and health equity (DeSalvo et al., 2017).

$\mathrm{MCH}$ professionals have opportunities to advance health equity through cross-sector collaboration by actively pursuing involvement in HIA taking place in their respective jurisdictions and strategically considering it as a means for addressing issues relevant to their stakeholders and communities. Where HIAs are more common, there appears to be opportunity for intentionally integrating $\mathrm{MCH}$ perspectives into ongoing cross-sector collaborations addressing health determinants of significance for $\mathrm{MCH}$ outcomes. Where HIAs are less common, there may be opportunities for $\mathrm{MCH}$ leaders to initiate or strengthen those critical collaborations through the use of this specific tool. As practice continues to coalesce around advancing health equity, both in $\mathrm{MCH}$ efforts and through the HIA process, opportunities for collaboration will emerge and can be leveraged to advance population health outcomes for $\mathrm{MCH}$ populations. Collaborative cross-sector opportunities are not exclusive to HIA, and future research could expand upon the current review to further explore roles for $\mathrm{MCH}$ in other HiAP approaches.

HIA practitioners have opportunities to more actively seek engagement with MCH stakeholders, which could lead to broader applicability of HIA findings and recommendations. Incorporating more intentional $\mathrm{MCH}$ perspectives within HIA could be a mechanism to garner broader stakeholder and community engagement, which in turn can raise visibility of strategic approaches to population health and health equity. There could also be practical benefits in terms of access to and interpretation of MCH-relevant data that might otherwise be absent in a given assessment. Incorporating this perspective could strengthen the recommendations that are a primary output of the HIA process.

Although not coded as a key variable for this analysis, reviewers noted general $\mathrm{MCH}$ implications of recommendations in roughly two thirds of HIAs. If Title $\mathrm{V}$ or other $\mathrm{MCH}$ professionals are engaged in developing these recommendations, they can better ensure strategic relevance for $\mathrm{MCH}$ stakeholders and alignment with other $\mathrm{MCH}$ activities in a given jurisdiction. For example, with Title $\mathrm{V}$ involvement, an HIA could move past general discussions of an MCH-related issue to include NPM-specific data and strategies, resulting in direct advancement of relevant existing Title $\mathrm{V}$ priorities.

Intra-sector silos within public health may provide one explanation for underrepresentation of MCH stakeholders in HIA practice. When led by public health entities, HIAs are often housed within an environmental health or chronic disease unit; though in recent years, HIAs led by offices focused on evaluation, policy, or equity have become more common (J. Dills, personal communication, April 1, 2020). This assignment of HIA responsibility to
Table 5 Distribution of HIAs by sector

\begin{tabular}{lcc}
\hline Sector (as defined in source database) & $\begin{array}{l}\text { Percent of all HIAs } \\
\text { included in review } \\
(\mathrm{n}=350)\end{array}$ & $\begin{array}{l}\text { Percent of HIAs with clear MCH } \\
\text { Stakeholder involvement }(\mathrm{n}=84)\end{array}$ \\
\hline Agriculture, food and drug & 8.6 & 15.5 \\
Built environment & 35.1 & 29.8 \\
Education & 4.0 & 13.1 \\
Housing & 7.7 & 6.0 \\
Labor \& Employment & 4.6 & 7.1 \\
Natural resources \& energy & 6.9 & 2.4 \\
Transportation & 21.4 & 14.3 \\
Other* & 11.7 & 11.8 \\
\hline
\end{tabular}

*Includes the following sector designations, which each representing less than 10 HIAs in the sample: climate change, community development, criminal justice, economic policy, gambling, physical activity, and water 
specific public health content areas might raise barriers to supporting active involvement of $\mathrm{MCH}$ professionals from within an agency, among other bureaucratic challenges. Without active attempts to bridge these intra-sector silos and address these challenges, HIA work done by one arm of a public health agency can easily occur in isolation from the other. As MCH leaders become more engaged in upstream policy work, awareness of opportunities to leverage existing cross-sector experience from within their own agencies is an asset. HIAs potentially present this type of opportunity, as do HiAP approaches more broadly (Rudolph et al., 2013). A more thorough examination of variation in resources available to support HIA over time is beyond the scope of this review; however, future research could determine if greater availability of resources to support HIA is associated with greater likelihood of $\mathrm{MCH}$ inclusion in those HIAs.

In terms of connecting to sectors outside of public health, Table 5 shows the distribution of HIAs by target sector. HIAs aimed at informing decisions related to agriculture/food systems, education, and labor/employment have included $\mathrm{MCH}$ stakeholders more regularly than HIAs targeting other sectors, but all sectors have included MCH stakeholders to some degree. These data are included to demonstrate the breadth of sectors covered by HIAs generally and to note the sectors most common to HIAs that specifically include $\mathrm{MCH}$ stakeholders. This review does not consider the temporality of $\mathrm{MCH}$ involvement in HIA and the MCH-relevant content contained therein. Some decisions considered by HIAs may be more directly tied to $\mathrm{MCH}$ populations and have a readily apparent reason to include $\mathrm{MCH}$ practitioners, leading to more $\mathrm{MCH}$-relevant content in those HIAs. For example, decisions made in the education sector are likely to influence children, so an HIA of those decisions may naturally include some level of $\mathrm{MCH}$ perspectives from the outset. As a collaborative approach, different perspectives inform HIAs throughout the process, with the screening and scoping stages as the most opportune time for robust $\mathrm{MCH}$ involvement that would potentially guide assessment and recommendations toward more MCH-relevant content.

\section{Limitations}

Three interrelated limitations should be considered in interpreting these findings. First, approximately one in six HIAs listed in the Health Impact Project database did not have the publicly available documentation needed to be included in this analysis. Further, the database is populated mostly by voluntary self-reports from the HIA field, and thus, an unknown number of HIAs in the U.S. are not included in the data. How information from these HIAs might influence study results is unclear. Second, thoroughness of available HIA documentation varies widely (Rhodus et al., 2013). HIA is both a process and a report. This review only judged aspects of the process based on how well the associated reports (and other available documentation) described them. This limitation leads to an incomplete picture of HIAs that may have had a more robust process than reflected in their final reports and could have led to underestimating $\mathrm{MCH}$ stakeholder involvement. Finally, because of the exploratory nature of this review, the research team erred on the side of inclusivity when coding HIA content. Regular discussions of the data as they were being collected and resulting iterations of the review protocol may have introduced increased subjectivity in comparison to a more traditional systematic review of research studies. Future research examining involvement of $\mathrm{MCH}$ stakeholders in HIA practice could address some of these limitations by including interviews with leaders of and participants in specific HIAs.

\section{Conclusion}

HIA is an established tool that supports prospective engagement by public health stakeholders in non-health decisionmaking contexts. This exploratory review indicates limited involvement of $\mathrm{MCH}$-focused practitioners in HIA practice to date. The results reveal that despite this lack of engagement, a large portion of HIA practice considers populations and measures with clear relevance to $\mathrm{MCH}$. When the $\mathrm{MCH}$ workforce is involved, HIAs are significantly more likely to include specific MCH content. Therefore, intentional alignment of $\mathrm{MCH}$ and HIA practice, along with capacity building to support use of HIA by MCH stakeholders, would potentially reinforce strategies seeking to inform decisions made in other sectors. As noted earlier, these decisions influence social determinants of health, the inequitable distribution of which underpin many health disparities. HIA is one method through which public health perspectives can be integrated into these influential decisions for population health. Limited involvement of $\mathrm{MCH}$ practitioners in HIA points to a missed opportunity to ensure that their particular perspectives on public health are actionably included in these cross-sector collaborations to address social determinants. 


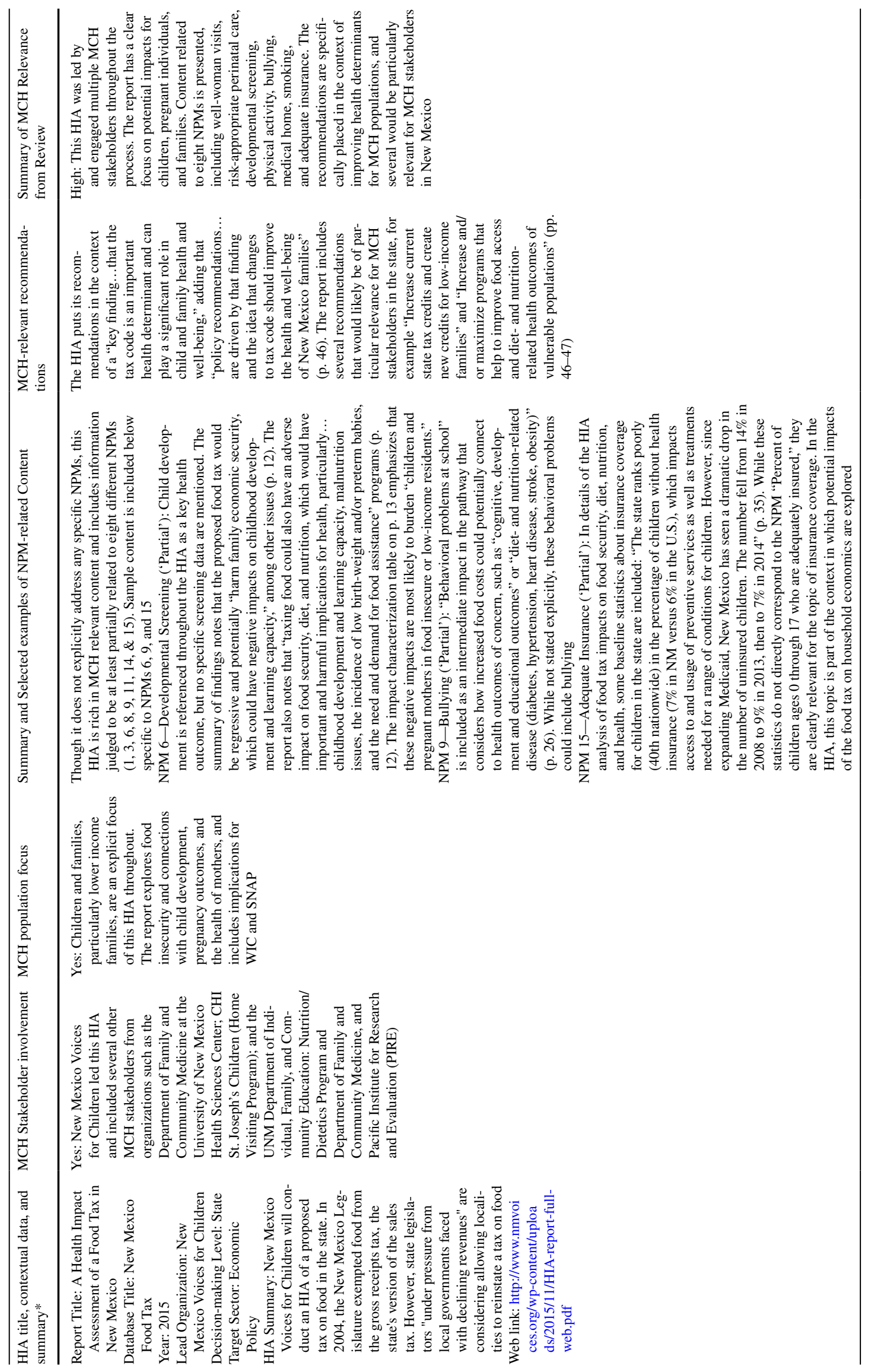




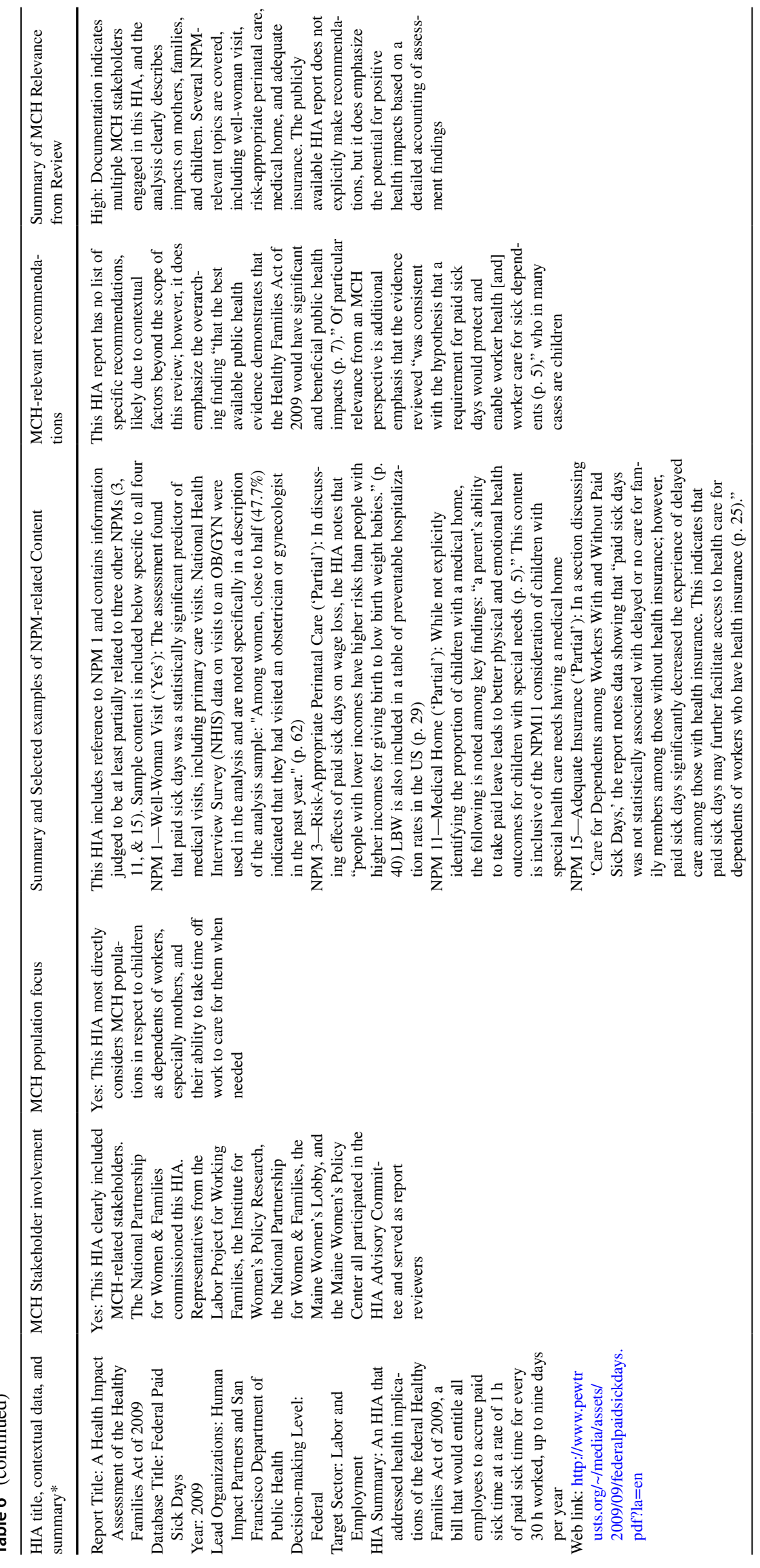




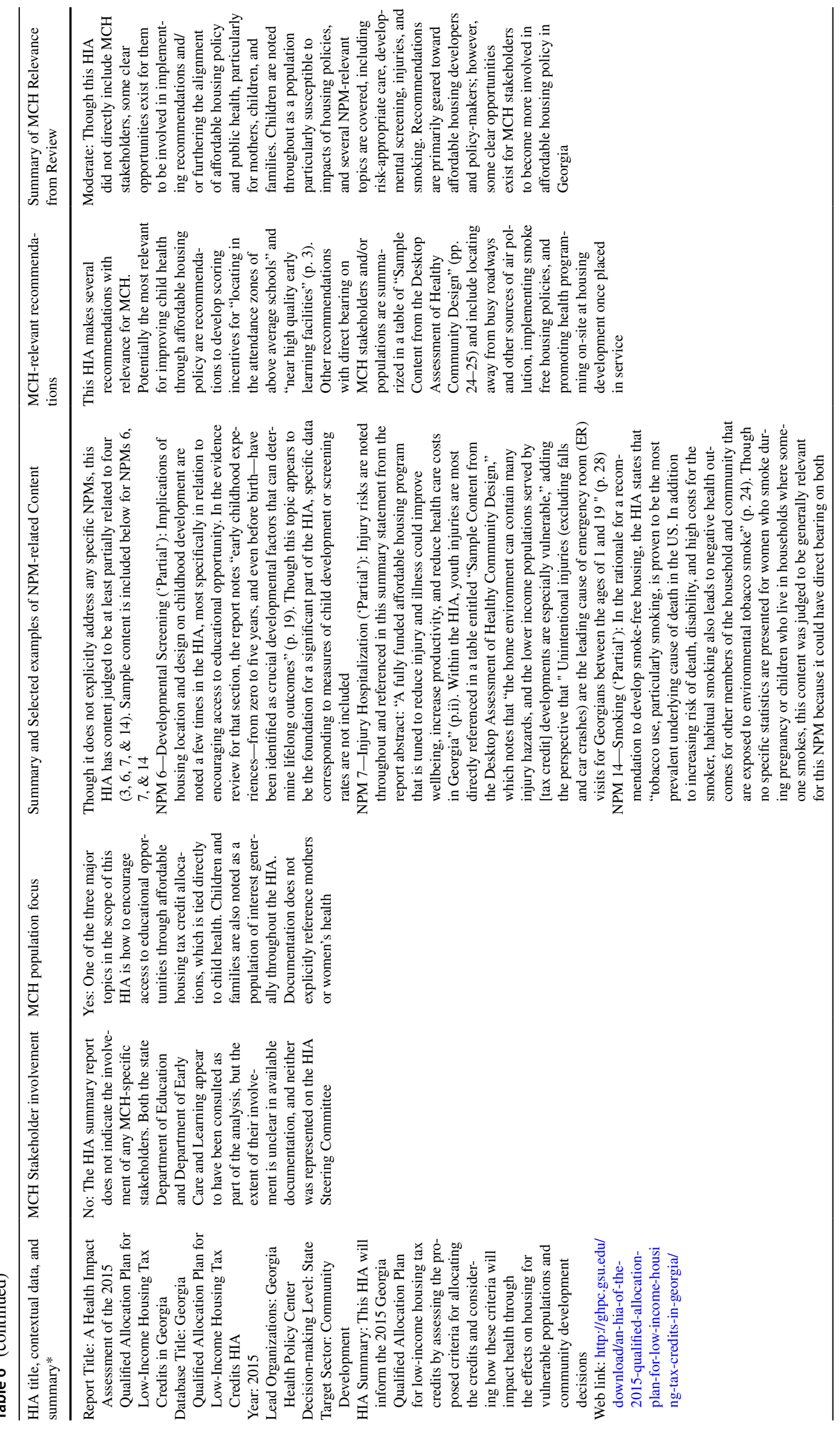




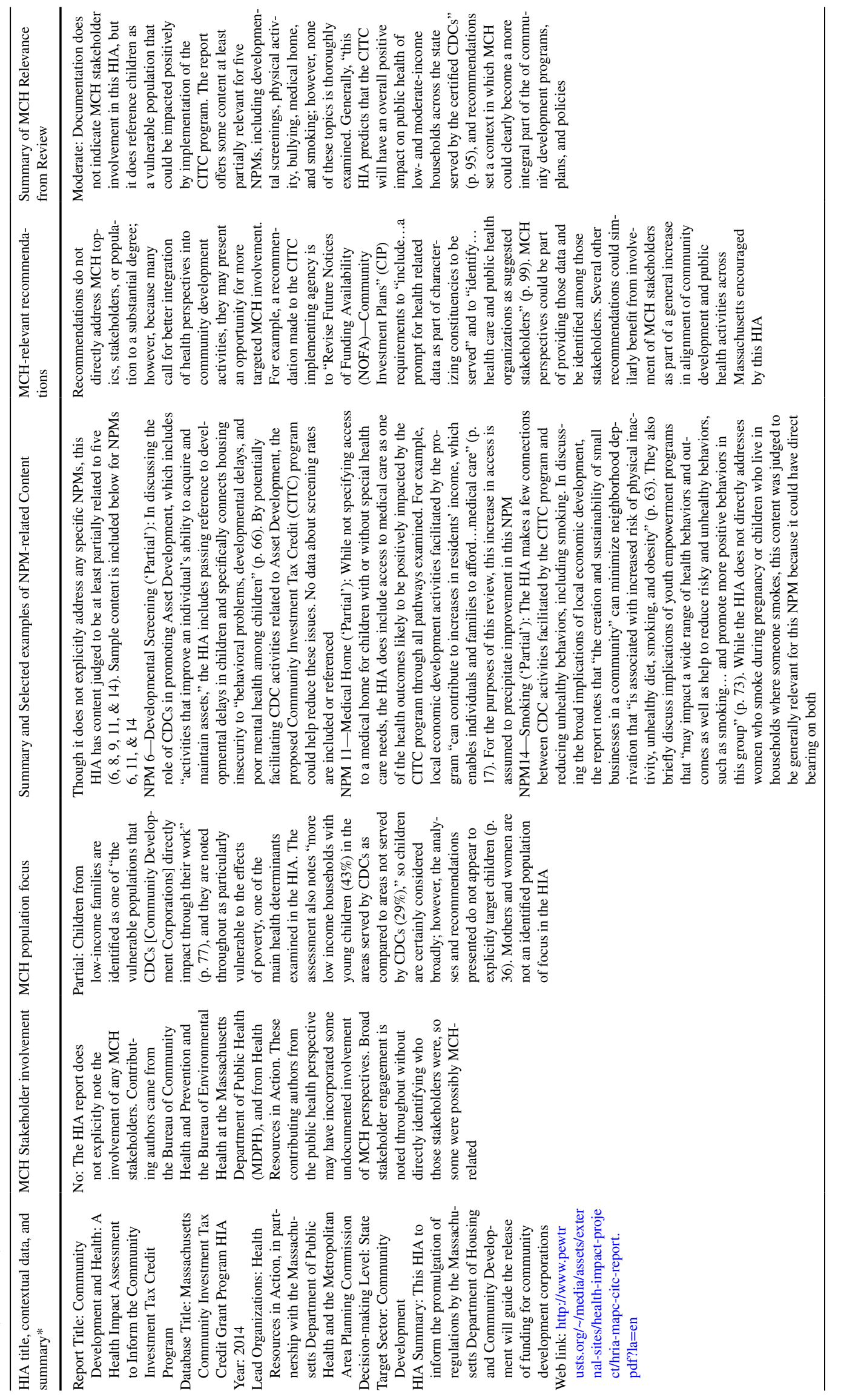




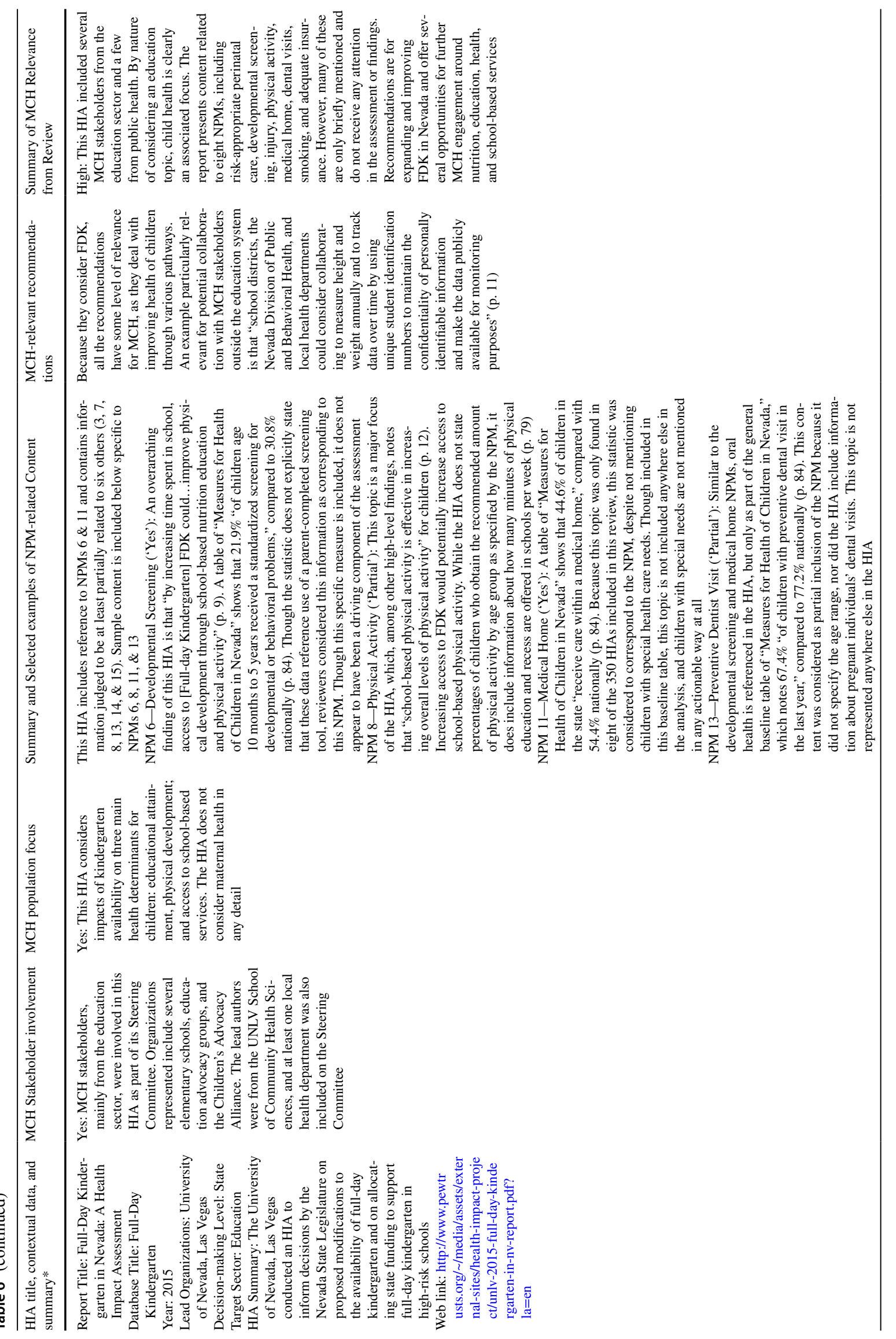




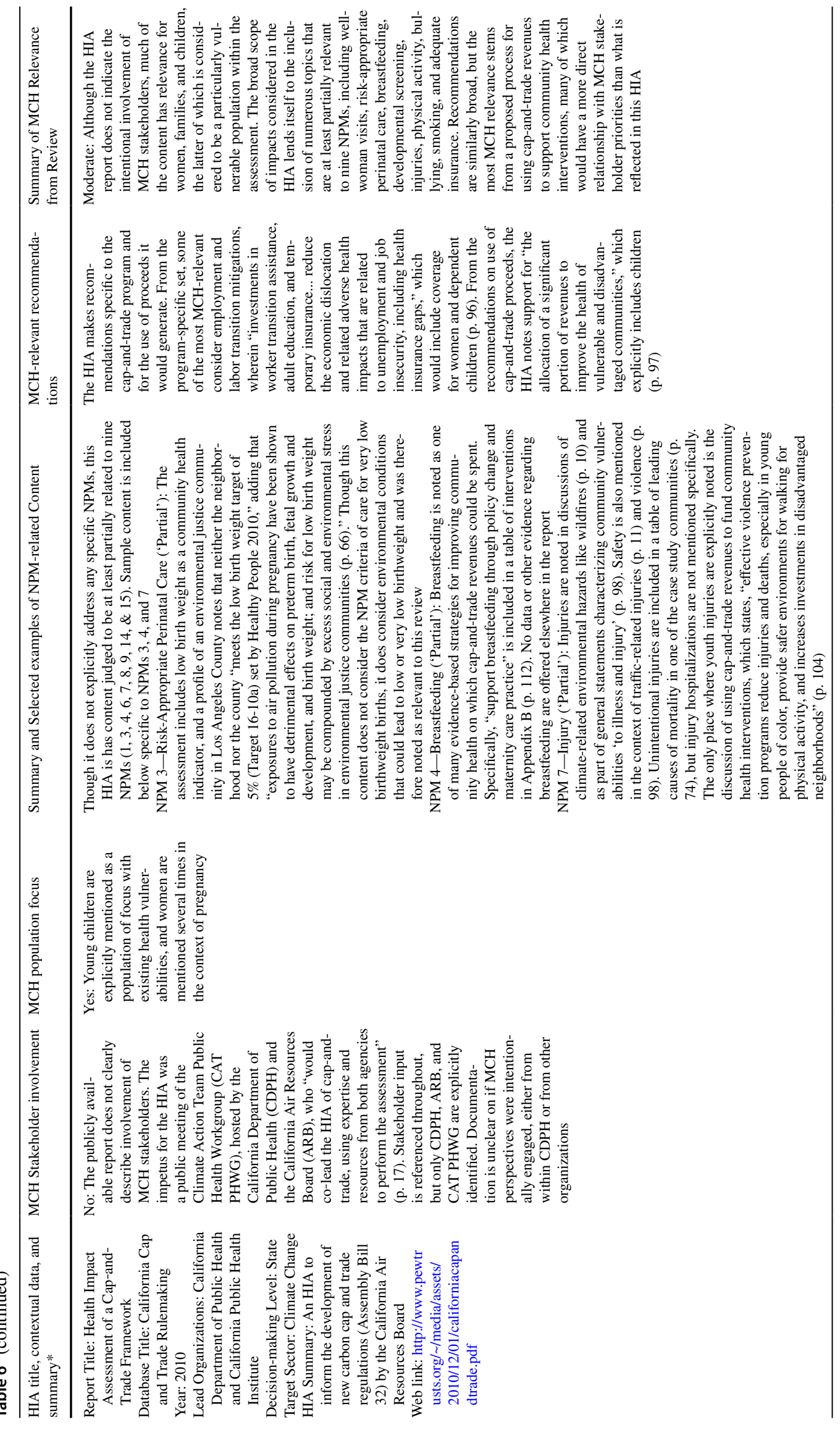




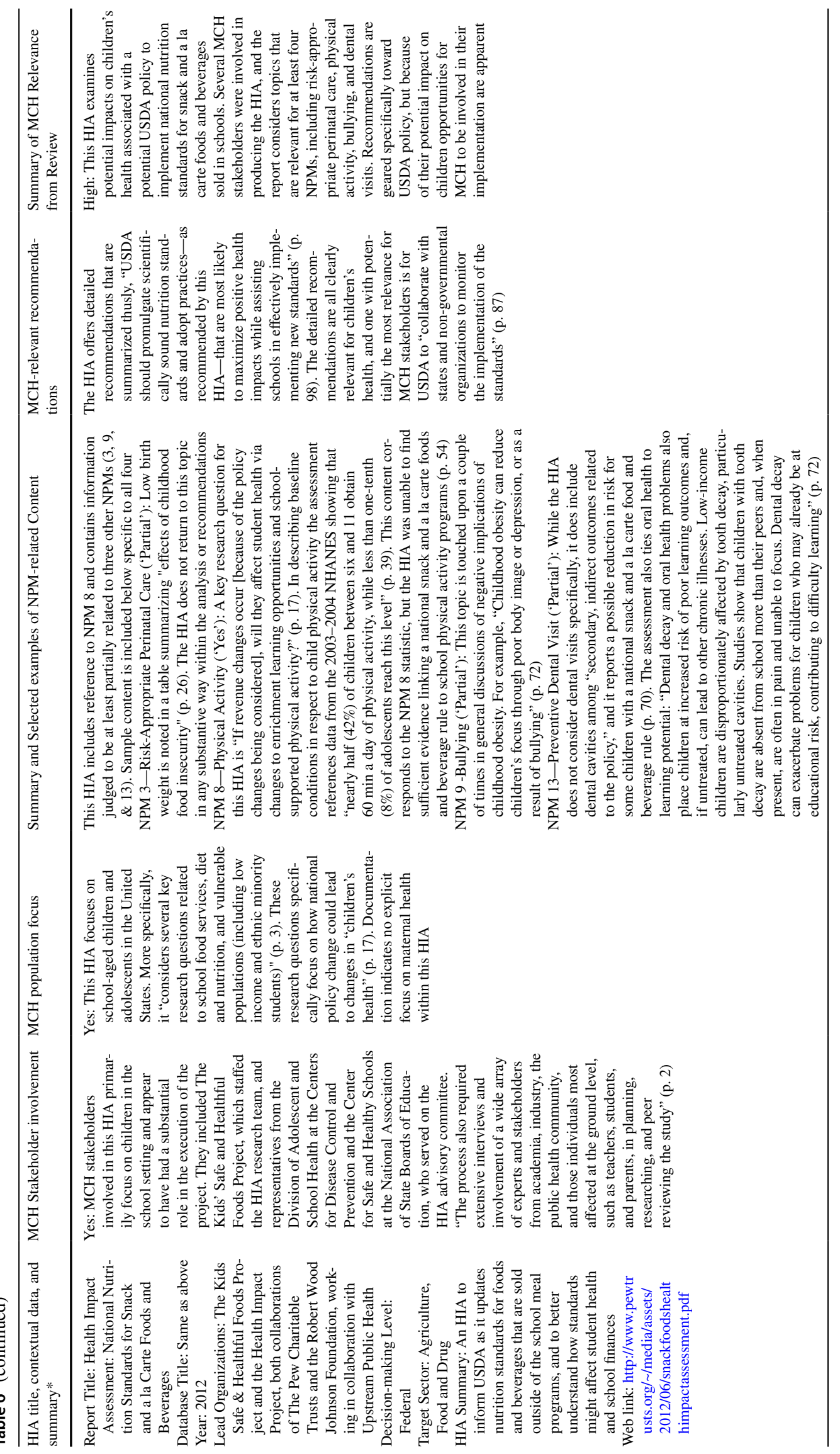




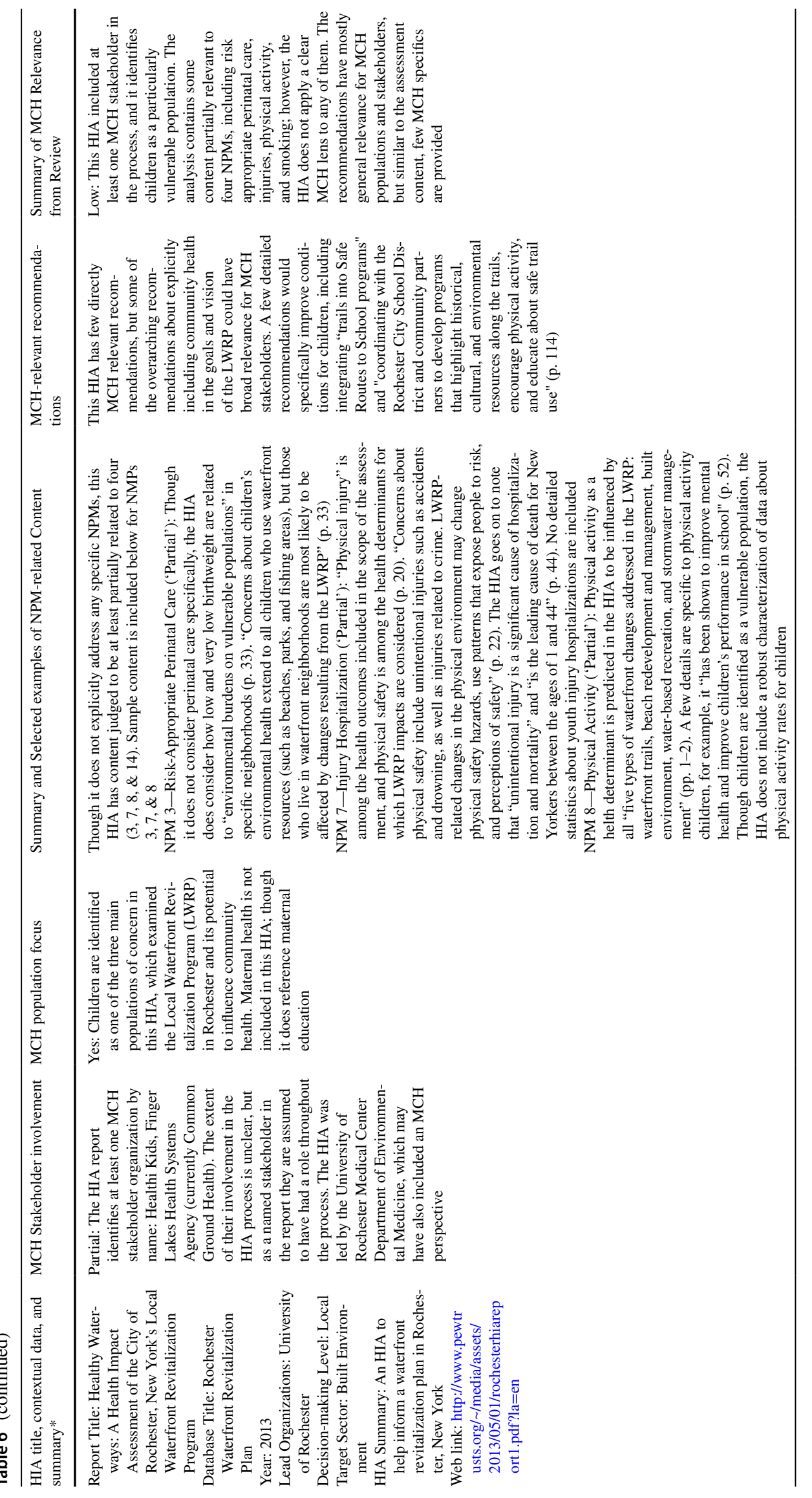




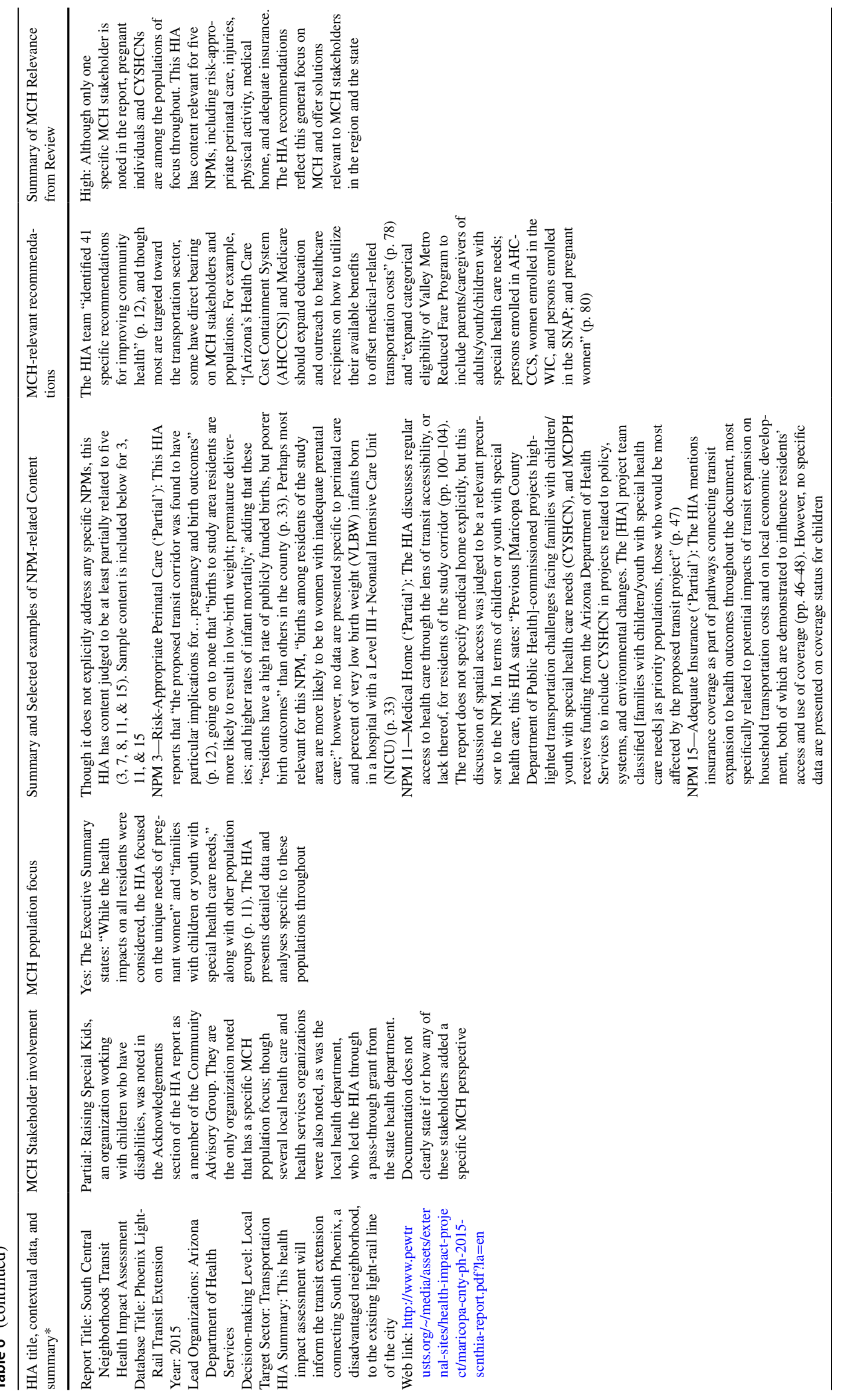




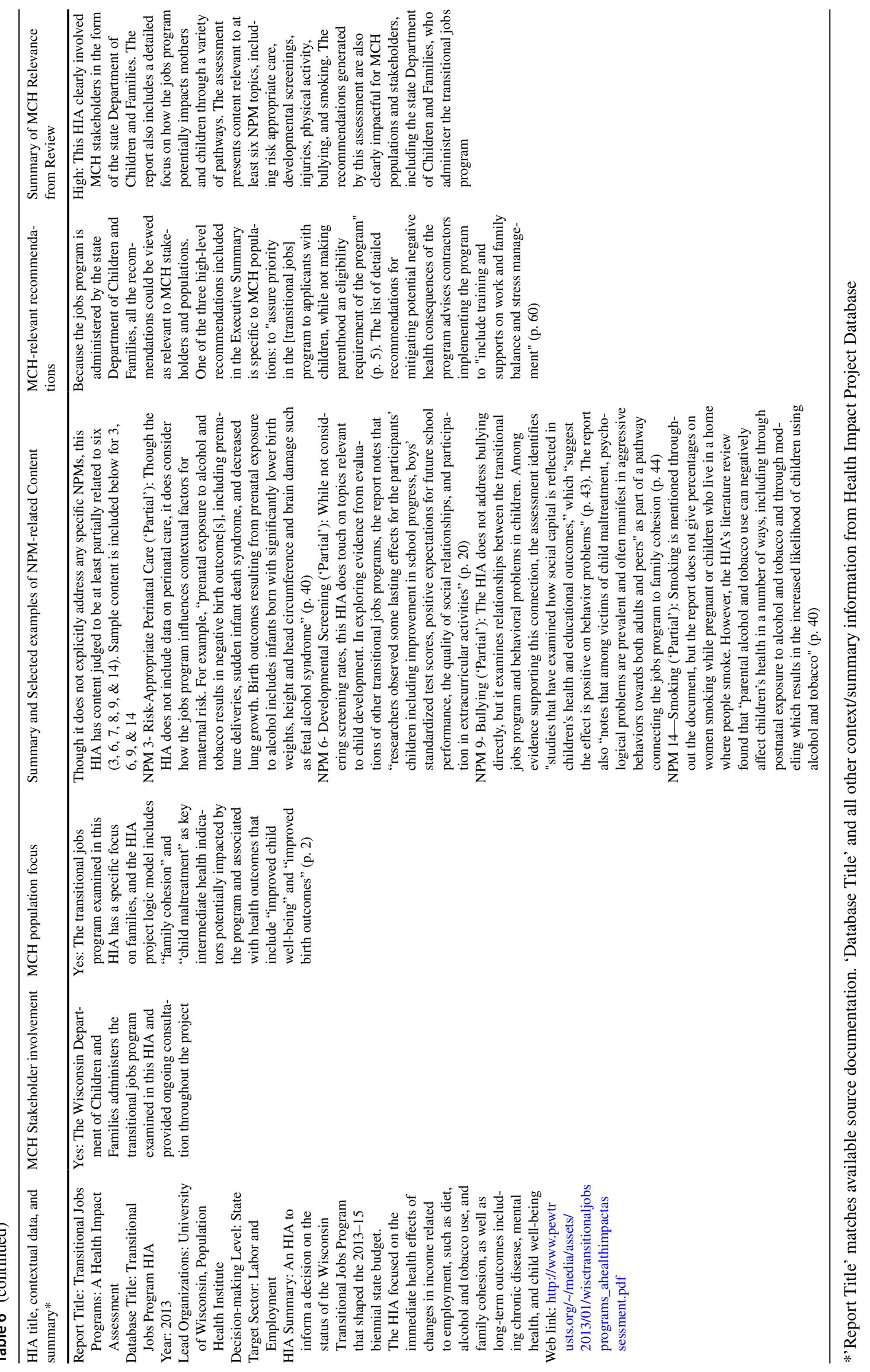


Acknowledgements The authors would like to acknowledge the valuable contributions of Eric Morrisey and Taylor Williams, Georgia State University School of Public Health Practicum Students who assisted in the formulation of this review, and of Becky Ofrane, who contributed as a Society of Practitioners of Health Impact Assessment Practitioner Exchange Participant. The authors would also like to thank the National $\mathrm{MCH}$ Workforce Development Center's Systems Integration Core for their valuable feedback on iterations of this effort.

Author Contributions JED contributed to all components of this manuscript from conception to submission. TML conducted the review and analysis of data in collaboration with JD. JB, AM, and KHL reviewed content and made additional contributions to the final work.

Funding This project is supported by the Health Resources and Services Administration (HRSA) of the U.S. Department of Health and Human Services (HHS) under Grant Number UE7MC26282 National $\mathrm{MCH}$ Workforce Development Center Cooperative Agreement. This information or content and conclusions are those of the author and should not be construed as the official position or policy of, nor should any endorsements be inferred by HRSA, HHS, or the U.S. Government.

\section{Declarations}

Conflict of interest The authors have no conflicting or competing interests to disclose.

\section{Consent to participate Not applicable.}

Consent for publication Not applicable.

Open Access This article is licensed under a Creative Commons Attribution 4.0 International License, which permits use, sharing, adaptation, distribution and reproduction in any medium or format, as long as you give appropriate credit to the original author(s) and the source, provide a link to the Creative Commons licence, and indicate if changes were made. The images or other third party material in this article are included in the article's Creative Commons licence, unless indicated otherwise in a credit line to the material. If material is not included in the article's Creative Commons licence and your intended use is not permitted by statutory regulation or exceeds the permitted use, you will need to obtain permission directly from the copyright holder. To view a copy of this licence, visit http://creativecommons.org/licenses/by/4.0/.

\section{References}

Bhatia, R., Farhang, L., Heller, J., Lee, M., Orenstein, M., Richardson, M., \& Wernham, A. (2014). Minimum elements and practice standards for health impact assessment, version 3. Retrieved from https://hiasociety.org/resources/Documents/HIA-Practice-Stand ards-September-2014.pdf.

Bogaert, K., Castrucci, B. C., Gould, E., Sellers, K., Leider, J. P., Whang, C., \& Whitten, V. (2019). The Public Health Workforce Interests and Needs Survey (PH WINS 2017): An expanded perspective on the state health agency workforce. Journal of Public Health Management and Practice, 25, S16-S25.

Braveman, P. (2014). What are health disparities and health equity? We need to be clear. Public Health Reports (washington, D.c.: 1974), 129(Suppl 2), 5-8. https://doi.org/10.1177/00333549141291S203

Clarke, A. N., \& Cilenti, D. (2018). Developing collaborative maternal and child health leaders: A descriptive study of the national maternal and child health workforce development center. Maternal and Child Health Journal, 22(1), 17-23.

Cole, B. L., \& Fielding, J. E. (2007). Health impact assessment: A tool to help policy makers understand health beyond health care. Annual Review of Public Health, 28(1), 393-412. https://doi.org/ 10.1146/annurev.publhealth.28.083006.131942

Cole, B. L., MacLeod, K. E., \& Spriggs, R. (2019). Health impact assessment of transportation projects and policies: Living up to aims of advancing population health and health equity? Annual Review of Public Health, 40, 305-318. https://doi.org/10.1146/ annurev-publhealth-040617-013836

Cowling, K., Lindberg, R., Dannenberg, A. L., Neff, R. A., \& Pollack, K. M. (2017). Review of health impact assessments informing agriculture, food, and nutrition policies, programs, and projects in the United States. Journal of Agriculture, Food Systems, and Community Development, . https://doi.org/10.5304/ jafscd.2017.073.009

Dannenberg, A. L. (2016a). A brief history of health impact assessment in the United States. Chronicles of Health Impact Assessment. https://doi.org/10.18060/21348

Dannenberg, A. L. (2016b). Effectiveness of health impact assessments: A synthesis of data from five impact evaluation reports. Preventing Chronic Disease. https://doi.org/10.5888/pcd13. 150559

Dannenberg, A. L., Rogerson, B., \& Rudolph, L. (2019). Optimizing the health benefits of climate change policies using health impact assessment. Journal of Public Health Policy, 41, 139-154.

DeSalvo, K. B., O’Carroll, P. W., Koo, D., Auerbach, J. M., \& Monroe, J. A. (2016). Public health 3.0: Time for an upgrade. American Journal of Public Health, 106(4), 621.

DeSalvo, K. B., Wang, Y. C., Harris, A., Auerbach, J., Koo, D., \& O'Carroll, P. (2017). Public health 3.0: A call to action for public health to meet the challenges of the 21 st century. Preventing Chronic Disease, 14, E78-E78. https://doi.org/10.5888/pcd14. 170017

Fine, A., \& Kotelchuck, M. (2010). Rethinking MCH: The life course model as an organizing framework. US Department of Health and Human Services, Health Resources and Services Administration, Maternal and Child Health Bureau, 1-20.

Gase, L. N., Pennotti, R., \& Smith, K. D. (2013). "Health in All Policies": Taking stock of emerging practices to incorporate health in decision making in the United States. Journal of Public Health Management and Practice, 19(6), 529-540.

Gase, L. N., DeFosset, A. R., Gakh, M., Harris, C., Weisman, S. R., \& Dannenberg, A. L. (2017). Review of education-focused health impact assessments conducted in the United States. Journal of School Health, 87(12), 911-922.

Health Impact Project. (2017). Health impact assessments in the United States. Retrieved from http://www.pewtrusts.org/en/research-andanalysis/data-visualizations/2015/hia-map.

IBM Corp. (2017). IBM SPSS Statistics for Windows, Version 25.0. Armonk, NY: IBM Corp.

Kogan, M. D., Dykton, C., Hirai, A. H., Strickland, B. B., Bethell, C. D., Naqvi, I., Cano, C. E., Downing-Futrell, S. L., \& Lu, M. C. (2015). A new performance measurement system for maternal and child health in the United States. Maternal and Child Health Journal, 19(5), 945-957.

Koh, H. K., Piotrowski, J. J., Kumanyika, S., \& Fielding, J. E. (2011). Healthy people: A 2020 vision for the social determinants approach. Health Education \&amp; Behavior, 38(6), 551-557. https://doi.org/10.1177/1090198111428646

Margolis, L., Mullenix, A., Apostolico, A. A., Fehrenbach, L. M., \& Cilenti, D. (2017). V workforce development in the era of health transformation. Maternal and Child Health Journal, 21(11), 2001-2007. 
Mattessich, P. W., \& Rausch, E. J. (2014). Cross-sector collaboration to improve community health: A view of the current landscape. Health Affairs, 33(11), 1968-1974.

National Research Council. (2011). Improving health in the United States: The role of health impact assessment. National Academies Press.

Raskind, I. G., Chapple-McGruder, T., Mendez, D. D., Kramer, M. R., Liller, K. D., Cilenti, D., Wingate, M. S., Castrucci, B. C., Gould, E., \& Stampfel, C. (2019). MCH workforce capacity: Maximizing opportunities afforded by a changing public health system. Maternal and Child Health Journal. https://doi.org/10.1007/ s10995-018-02728-7

Rhodus, J., Fulk, F., Autrey, B., O'Shea, S., \& Roth, A. (2013). A review of health impact assessments in the U.S.: Current stateof-science, best practices, and areas for improvement. Retrieved from https://www.epa.gov/sites/production/files/2015-03/docum ents/review-hia.pdf.

Rudolph, L., Caplan, J., Ben-Moshe, K., \& Dillon, L. (2013). Health in all policies: A guide for state and local governments. American Public Health Association Washington (DC).

Sellers, K., Leider, J. P., Harper, E., Castrucci, B. C., Bharthapudi, K., Liss-Levinson, R., Jarris, P. E., \& Hunter, E. L. (2015). The public health workforce interests and needs survey: The first national survey of state health agency employees. Journal of Public Health Management and Practice, 21(Suppl 6), S13.
Sohn, E. K., Stein, L. J., Wolpoff, A., Lindberg, R., Baum, A., McInnisSimoncelli, A., \& Pollack, K. M. (2018). Avenues of influence: The relationship between health impact assessment and determinants of health and health equity. Journal of Urban Health, 95(5), $754-764$.

Ståhl, T., Wismar, W. , Ollila, E. , Lahtinen, E. \& Leppo, K. (Eds) (2006). Health in All Policies: Prospects and Potentials. Ministry of Social Affairs and Health, Helsinki, Finland.

Stone, C. (2016). Letter from the Editor. Chronicles of Health Impact Assessment, 1(1). Retrieved from https://journals.iupui.edu/index. $\mathrm{php} / \mathrm{chia} /$ issue/view/1239/337.

U.S. Department of Health and Human Services Office of Disease Prevention and Health Promotion. (n.d.). Healthy People 2020. Retrieved from https://www.healthypeople.gov/2020/topics-objec tives/topic/social-determinants-of-health?topicid $=39$

Vermont Department of Health. (2015). A health impact assessment of paid sick leave in vermont. Retrieved from http://www.pewtrusts. org/ /media/assets/external-sites/health-impact-project/vt-doh2015-paid_sick_leave-report.pdf?la=en.

Wernham, A., \& Teutsch, S. M. (2015). Health in all policies for big cities. Journal of Public Health Management and Practice, 21(Suppl 1), S56.

Publisher's Note Springer Nature remains neutral with regard to jurisdictional claims in published maps and institutional affiliations. 